
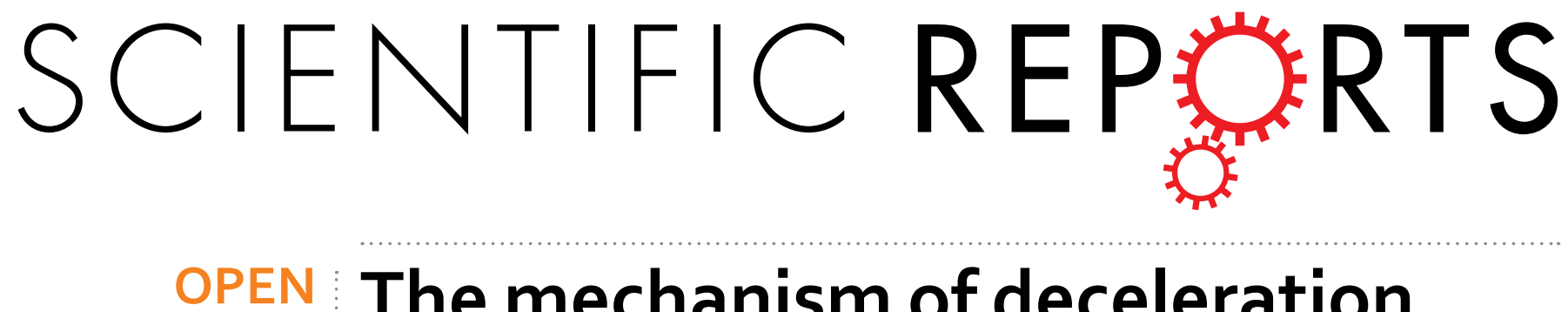

\title{
The mechanism of deceleration of nucleation and crystal growth by the small addition of transition
}

Received: 28 January 2016

Accepted: 15 April 2016

Published: 06 May 2016

\section{metals to lithium disilicate glasses}

\author{
Katrin Thieme ${ }^{1}$, Isak Avramov ${ }^{2} \&$ Christian Rüssel $^{1}$
}

The addition of small amounts of niobium or tantalum oxide to lithium disilicate glass provokes a drastic decrease of the steady-state nucleation rates and the crystal growth velocities. The viscosity of the residual glassy matrix is considered as a function of the crystallization degree in the course of a nonisothermal crystallization. For simplification, a homogeneous distribution of the added oxides in the glass matrix is assumed. While the viscosity initially decreases, it significantly increases again for higher crystallization degrees hindering crystal growth. However, it was shown that the additives are enriched at the crystal interface. Several possible reasons for the inhibition of nucleation and growth kinetics such as viscosity, interfacial energy crystal/glassy phase, thermodynamic driving force or impingement rate are discussed. Since the crystallization front is blocked by the additives the impingement rate is decreased with increasing additive concentration. Since small concentrations of $\mathrm{Nb}_{2} \mathrm{O}_{5}$ and $\mathrm{Ta}_{2} \mathrm{O}_{5}$ have a drastic effect on the nucleation, these components should be enriched at the interface crystal/glass. This will only take place, if it leads to a decrease in the interfacial energy. Since this effect alone should result in an increase of the nucleation rate, it must be overcompensated by kinetic effects.

In the past decades, nucleation and crystal growth kinetics of glasses has been intensively studied, preferentially in isochemical systems where the crystalline phase possesses the same chemical composition as the parent glass. One of the model systems for homogeneous nucleation is stoichiometric lithium disilicate glass as detailed thermodynamic and kinetic data are available ${ }^{1-6}$. In isochemical systems, the composition of the glass remains constant during nucleation and the crystal growth velocity is time-independent. Strictly spoken, each glass always contains more or less high quantities of impurities, and hence a system cannot be ideally isochemical. The impurities are either incorporated into the crystal or are enriched at the crystallization front leading to the formation of concentration gradients which decelerate crystal growth. In the latter case, the chemical composition of the residual glassy matrix changes during the course of crystallization. It is also possible that the viscosity in a diffusion layer around the crystals increases resulting in the formation of a diffusion barrier, i.e. in the decrease of the diffusion coefficients which also decelerates crystal growth ${ }^{7-12}$. The occurrence of self-limited crystal growth in some glass systems was theoretically described ${ }^{13-15}$ and diffusion barriers surrounding growing crystals have been experimentally proven ${ }^{16-20}$. However, the viscosity at the interface can also be lowered by the occurrence of network modifiers leading to an increased mobility and hence to a higher crystal growth velocity ${ }^{13}$. It is also observed for Fe-Mn-O nanoparticles in a $\mathrm{SiO}_{2} / \mathrm{Na}_{2} \mathrm{O} / \mathrm{Fe}_{2} \mathrm{O}_{3} / \mathrm{MnO}$ glass that the formation of a rigid shell around crystals does not impair the diffusion of the ions which is related to a decreased glass transition temperature of the shell region ${ }^{21}$. The effect of small amounts of oxides (e.g. $\mathrm{ZrO}_{2}^{22,23}, \mathrm{TiO}_{2}{ }^{24,25}$ ) added to specific glass compositions in order to promote nucleation has intensively been investigated in the past. However, the contrary effect of nucleation inhibition has only been scarcely investigated. Recently, it was shown that 1 or $2 \mathrm{~mol} \% \mathrm{Al}_{2} \mathrm{O}_{3}, \mathrm{La}_{2} \mathrm{O}_{3}$, $\mathrm{TiO}_{2}{ }^{26}, \mathrm{ZrO}_{2}{ }^{27}, \mathrm{Nb}_{2} \mathrm{O}_{5}$ or $\mathrm{Ta}_{2} \mathrm{O}_{5}{ }^{28}$ may affect the nucleation and growth kinetics if added to stoichiometric lithium disilicate glass. Depending on the chosen additive and its concentration, the steady-state nucleation rates may be affected in various degrees. For example, adding $2 \mathrm{~mol} \%$ of $\mathrm{La}_{2} \mathrm{O}_{3}$ or $\mathrm{Nb}_{2} \mathrm{O}_{5}$ may provoke a decrease in the

${ }^{1}$ Otto-Schott-Institut für Materialforschung, Jena University, Fraunhoferstr. 6, 07743 Jena, Germany. ${ }^{2}$ Institute of Physical Chemistry, Bulgarian Academy of Science, Sofia, Bulgaria. Correspondence and requests for materials should be addressed to K.T. (email: katrin.thieme@uni-jena.de) 
nucleation rates by up to 3 orders of magnitude and an extreme increase of the induction times ${ }^{26,28}$. Moreover, the crystal growth velocities are drastically decreased.

Although the effect of nucleation inhibition has recently been experimentally described, the reasons for this effect are still unknown. Thus, we try to analyze whether several parameters such as viscosity, interfacial energy glass/crystal or the thermodynamic driving force may be considered as key factors for this effect. Moreover, the change in viscosity of the residual glass matrix is regarded as a function of the crystallization degree, for both isothermal and non-isothermal conditions.

\section{Experimental Section}

Glass preparation. Glasses with the compositions $c \mathrm{M}_{2} \mathrm{O}_{5} \cdot(100-\mathrm{c}) \mathrm{Li}_{2} \mathrm{Si}_{2} \mathrm{O}_{5}(\mathrm{c}=0.1,1$ or $2 \mathrm{~mol} \%, \mathrm{M}=\mathrm{Nb}$, $\mathrm{Ta}$ ) were prepared from the raw materials $\mathrm{SiO}_{2}$ (Sipur A1, Bremthaler Quarzitwerke), $\mathrm{Li}_{2} \mathrm{CO}_{3}$ (Polskie Odczynniki Chemiczne Gliwice), $\mathrm{Nb}_{2} \mathrm{O}_{5}$ (Ventron) and $\mathrm{Ta}_{2} \mathrm{O}_{5}$ (Alfa Aesar). The glass batches (usually for $200 \mathrm{~g}$ glass) were melted in a platinum crucible in the temperature range from 1450 to $1510^{\circ} \mathrm{C}$ in an inductive furnace for $0.5-1 \mathrm{~h}$ followed by a stirring process for $1.5 \mathrm{~h}$ using a frequency of $40-60 \mathrm{~min}^{-1}$. Afterwards the melts were soaked for further $15 \mathrm{~min}$ at the same temperature without stirring. In order to avoid crystallization during cooling two glass blocks were cast on a copper and brass block and subsequently transferred to a cooling furnace preheated to $475-495^{\circ} \mathrm{C}$. The furnace was immediately switched off allowing the glass to cool to room temperature and to release stresses. The prepared glasses were stored in a desiccator using $\mathrm{P}_{2} \mathrm{O}_{5}$ as drying agent.

Differential thermal analyses. For the determination of the glass transition and crystallization temperatures differential thermal analyses were performed using a SHIMADZU DTA 50 and a Linseis DSC PT1600. In order to minimize the effect of surface crystallization bulk samples were used. Here, $60 \mathrm{mg}$ glass powder was remelted in a DTA platinum crucible above the liquidus temperature for $5 \mathrm{~min}$ and then cooled in air. The remelted samples were heated with $10 \mathrm{~K} / \mathrm{min}$ to $1100^{\circ} \mathrm{C}$, kept for $15 \mathrm{~min}$ and cooled down with $10 \mathrm{~K} / \mathrm{min}$ to room temperature. After the measurements baseline corrections were made.

For the determination of the activation energy for crystallization, DSC scans with different heating rates in the range $5-20 \mathrm{~K} / \mathrm{min}$ were carried out. The activation energy of the overall crystallization process $\mathrm{E}$ was determined using the following equation ${ }^{29}$.

$$
\ln \left(\frac{\alpha}{T_{c}^{2}}\right)=-\left(\frac{E}{R T_{c}}\right)+\text { const. }
$$

where $\alpha$ is the heating rate, $\mathrm{T}_{\mathrm{c}}$ the peak crystallization temperature and $\mathrm{R}$ the gas constant. To estimate the melting enthalpies $\Delta \mathrm{H}_{\mathrm{m}}$, DSC scans with a heating rate of $20 \mathrm{~K} / \mathrm{min}$ up to $1100^{\circ} \mathrm{C}$ were performed. Since $\Delta \mathrm{H}_{\mathrm{m}}$ is proportional to the melting peak area, this value can be roughly determined using $\mathrm{DSC}^{30}$. In the case of the samples $\mathrm{Nb} 1$ and $\mathrm{Nb} 2$ two melting peaks occur due to surface and volume crystallization ${ }^{28}$. Possibly, there is a narrow fraction of very small crystals possessing a lower melting point. Therefore, the superimposed peaks were separated using the software Fityk and the areas of both peaks were determined and summated.

The glass transition temperatures $\mathrm{T}_{\mathrm{g}}$ of partially crystallized samples were determined by dilatometry. Therefore, cylindrical samples previously crystallized at a certain temperature for different holding times (Nb1 and Ta1: nucleation at $489^{\circ} \mathrm{C}$ for $2 \mathrm{~h}$ and growth at $640^{\circ} \mathrm{C}$; $\mathrm{Nb} 2$ : nucleation at $489^{\circ} \mathrm{C} 65 \mathrm{~h}$ and growth at $650^{\circ} \mathrm{C}$ ) were heated with $5 \mathrm{~K} / \mathrm{min}$ in a Netzsch DIL 420 PC.

Viscosity measurements. The viscosity measurements were performed using a rotation viscometer Bähr VIS $403\left(10^{1.3}\right.$ to $10^{3} \mathrm{dPa} \cdot \mathrm{s}$, rotation speed $250 \mathrm{~min}^{-1}$, cooling rate $\left.5 \mathrm{~K} / \mathrm{min}\right)$ and with a beam bending viscometer Bähr VIS $401\left(10^{9}\right.$ to $10^{12.5} \mathrm{dPa} \cdot \mathrm{s}$, heating rate $10 \mathrm{~K} / \mathrm{min}$, glass bars with the dimension $5 \times 5 \times 50$ and $\left.5 \times 4 \times 50 \mathrm{~mm}^{3}\right)$. The measured viscosities were fitted using the Avramov-Milchev-equation,

$$
\log \eta=\log \eta_{\infty}+\left(13-\log \eta_{\infty}\right)\left(\frac{T_{c}}{T}\right)^{\alpha}
$$

where the parameter $\eta_{\infty}$ describes the viscosity at $\mathrm{T} \rightarrow \infty$ and $\alpha$ is the dimensionless fragility parameter. $\mathrm{T}_{c}$ characterizes the temperature at which $\log \eta=13 \mathrm{dPa} \cdot \mathrm{s}$ and is close to the experimentally measured glass transition temperature $\mathrm{T}_{\mathrm{g}}$.

\section{Results}

Nucleation rates and crystal growth velocities of the glass $\mathrm{Nb0.1}$. In a recently published paper ${ }^{28}, 1$ or $2 \mathrm{~mol} \% \mathrm{Nb}_{2} \mathrm{O}_{5}$ or $\mathrm{Ta}_{2} \mathrm{O}_{5}$ were added to stoichiometric lithium disilicate glass resulting in drastically decreased steady-state nucleation rates by of up to three orders of magnitude. In order to analyze the effect of trace impurities, a lithium disilicate glass was doped with $0.1 \mathrm{~mol} \% \mathrm{Nb}_{2} \mathrm{O}_{5}$. The addition of the minor niobium concentration results only in a marginal decrease of the steady-state nucleation rates (Table 1), at which the maximum nucleation rate of Nb0.1 is slightly smaller than that of the undoped sample (13.52 and $16.331 /\left(\mathrm{mm}^{3} \cdot \mathrm{s}\right)$, respectively). However, the nucleation rates measured for $469-489^{\circ} \mathrm{C}$ are very similar and the typical drop of the nucleation rates after the maximum is not observed. The maximum nucleation rate is close to $\mathrm{T}_{\mathrm{g}}$ as it was also observed for the other glasses.

The crystal growth velocities of the studied glasses were determined by in situ hot stage microscopy and recently published in ref. 28. The crystal growth velocities of sample Nb0.1 are shown as a function of the temperature in Fig. 1a) (data in Table 2). It can be seen that the addition of $0.1 \mathrm{~mol} \% \mathrm{Nb}_{2} \mathrm{O}_{5}$ leads to a slight decrease of the crystal growth velocities which is then more pronounced with higher niobium concentrations. Since the 


\begin{tabular}{|l|c|c|c|c|}
\hline \multirow{2}{*}{$\mathbf{T}\left[{ }^{\circ} \mathbf{C}\right]$} & \multicolumn{2}{|c|}{$\mathbf{I}\left[\mathbf{1} /\left(\mathbf{m m}^{3} \cdot \mathbf{s}\right)\right]$} & \multicolumn{2}{|c|}{$\mathbf{t}_{\text {ind }}[\mathbf{m i n}]$} \\
\cline { 2 - 5 } & $\mathbf{A}^{\mathbf{a}}$ & $\mathbf{N b 0 . 1}$ & $\mathbf{A}^{\mathbf{a}}$ & $\mathbf{N b 0 . 1}$ \\
\hline 449 & 1.22 & ${ }^{\mathrm{b}}$ & 167 & $\mathrm{~b}$ \\
\hline 459 & 10.02 & 6.99 & 104 & 58 \\
\hline 469 & 16.33 & 13.51 & 25 & 14 \\
\hline 479 & 9.25 & 12.31 & - & - \\
\hline 489 & $\mathrm{~b}$ & 12.17 & $\mathrm{~b}$ & - \\
\hline
\end{tabular}

Table 1. Steady-state nucleation rates I and corresponding induction times $t_{\text {ind }}$ of the glass Nb0.1 compared with the base glass $A$ as a function of the temperature. $I$ and $t_{\text {ind }}$ were determined by a regression analysis (least squares method) with a correlation coefficient $\mathrm{R}^{2}>0.96$. In the case of the nucleation rates, there is an uncertainty of the last digit. ${ }^{\mathrm{a}}$ Values taken from ref. $26 .{ }^{\mathrm{b}}$ Not measured.
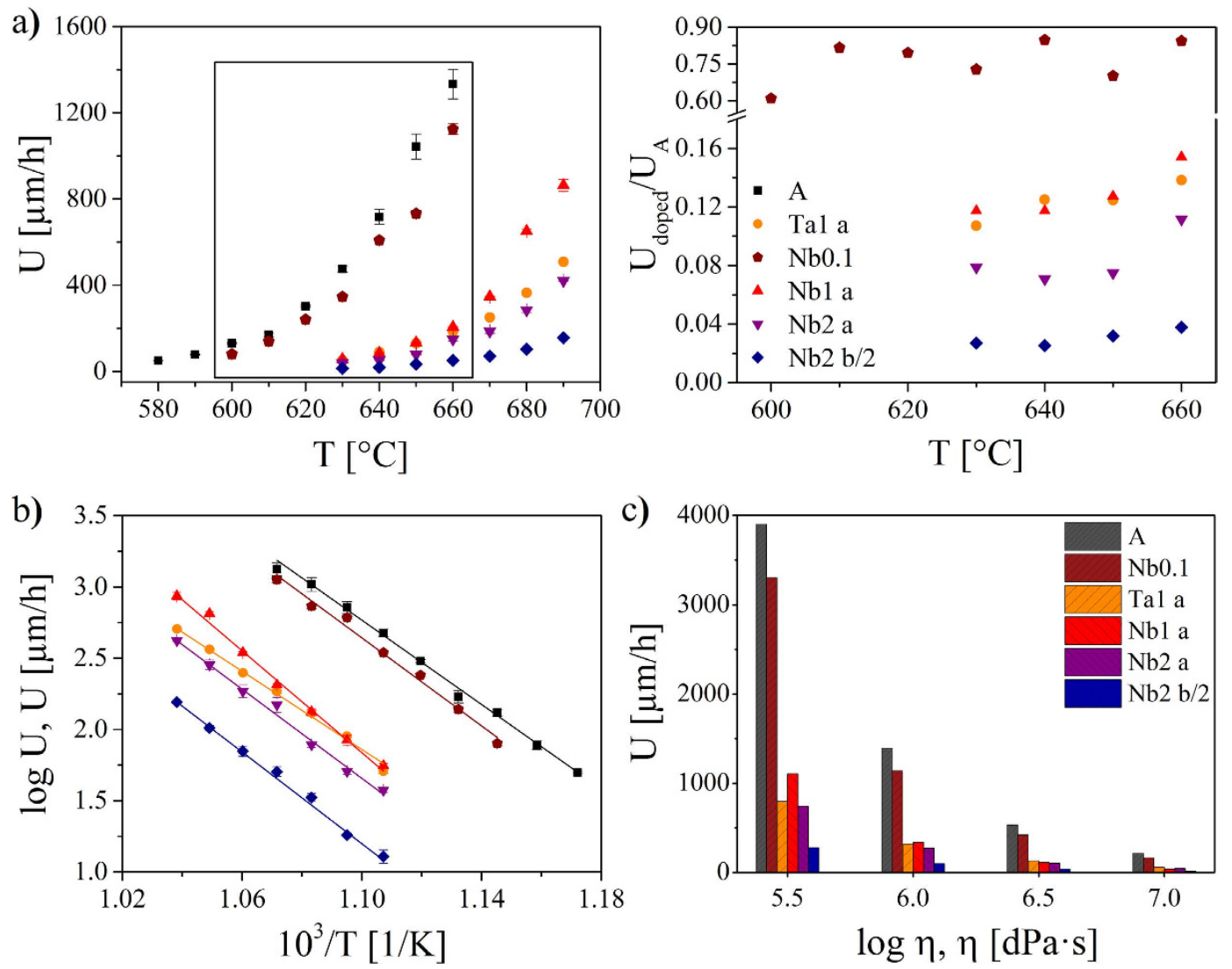

Figure 1. (a) Crystal growth velocities of the studied samples. In the case of samples Ta1, Nb1 and Nb2 different growth directions are considered. On the right hand side, the crystal growth velocities of the doped samples are related to those of sample A. In part (b) Arrhenius plots of the crystal growth velocity are shown while part (c) presents the crystal growth velocities as a function of the viscosity.

lithium disilicate crystals possess an ellipsoidal shape and get only a minimum constriction in their center during growth, the crystal growth velocities were not determined in different growth directions as it was the case for the samples $\mathrm{Ta} 1, \mathrm{Nb} 1$ and $\mathrm{Nb}_{2}{ }^{28}$. Moreover, due to the comparatively high nucleation rates, a separate nucleation heat treatment step previous to the measurement of the growth velocities was not required.

Variation in viscosity during crystallization. The crystals precipitated in samples Ta1, Nb1 and Nb2 show an approximately ellipsoidal shape with a main and a minor axis. In Fig. 1a), the crystal growth velocities are shown as a function of the temperature and growth direction (major axis a, minor axis b). It is obvious that the addition of up to $2 \mathrm{~mol} \% \mathrm{Nb}_{2} \mathrm{O}_{5}$ or $\mathrm{Ta}_{2} \mathrm{O}_{5}$ leads to a drastic decrease in the crystal growth velocities. While the crystal growth velocities of the samples $\mathrm{Ta} 1$ and $\mathrm{Nb} 1$ are almost the same in different growth directions, the crystal growth rates of sample $\mathrm{Nb} 2$ differ strongly. On the right hand side of Fig. 1a) the crystal growth velocities of the doped samples are related to those of samples A. With exception of sample $\mathrm{Nb} 0.1$, the ratio $\mathrm{U}_{\text {doped }} / \mathrm{U}_{\mathrm{A}}$ increases with increasing temperature and hence lower viscosity. According to Jackson's criteria of the interface, the crystal growth kinetics of materials with a large entropy of fusion $(\Delta S>4 R, R$ - gas constant), such as lithium disilicate, 


\begin{tabular}{|l|c|c|}
\hline \multirow{2}{*}{$\mathbf{T}\left[{ }^{\circ} \mathbf{C}\right]$} & \multicolumn{2}{|c|}{$\mathbf{U}[\mu \mathbf{m} / \mathbf{h}]$} \\
\cline { 2 - 3 } & $\mathbf{A}^{\mathrm{a}}$ & $\mathbf{N b 0 . 1}$ \\
\hline 580 & $50 \pm 1$ & - \\
\hline 590 & $78 \pm 3$ & - \\
\hline 600 & $131 \pm 3$ & $80 \pm 2$ \\
\hline 610 & $169 \pm 9$ & $138 \pm 3$ \\
\hline 620 & $302 \pm 4$ & $240 \pm 2$ \\
\hline 630 & $475 \pm 15$ & $346 \pm 4$ \\
\hline 640 & $717 \pm 34$ & $608 \pm 3$ \\
\hline 650 & $1,043 \pm 58$ & $732 \pm 15$ \\
\hline 660 & $1,332 \pm 69$ & $1,124 \pm 25$ \\
\hline $\mathrm{E}_{\mathrm{a}}[\mathrm{kJ} / \mathrm{mol}]$ & $283 \pm 4$ & $296 \pm 13$ \\
\hline
\end{tabular}

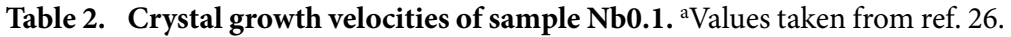

\begin{tabular}{|l|c|c|c|}
\hline Sample & Direction & $\mathbf{C}_{\mathbf{1}}$ & $\mathbf{C}_{2}[\mathbf{K}]$ \\
\hline $\mathrm{A}$ & & $19.1 \pm 0.2$ & $-14.8 \pm 0.2$ \\
\hline $\mathrm{Ta} 1$ & $\mathrm{a}$ & $16.9 \pm 0.4$ & $-13.7 \pm 0.4$ \\
\hline $\mathrm{Nb} 0.1$ & & $19.6 \pm 0.8$ & $-15.4 \pm 0.7$ \\
\hline $\mathrm{Nb} 1$ & $\mathrm{a}$ & $21.5 \pm 0.9$ & $-17.9 \pm 0.8$ \\
\hline $\mathrm{Nb} 2$ & $\mathrm{a}$ & $18.9 \pm 0.3$ & $-15.6 \pm 0.3$ \\
\hline & $\mathrm{b} / 2$ & $18.9 \pm 0.3$ & $-16.1 \pm 0.3$ \\
\hline
\end{tabular}

Table 3. Regression parameters determined by fitting the crystal growth velocities with the regression equation $\log \left(U, \frac{\mu m}{h}\right)=C_{1}+\frac{10^{3} \cdot C_{2}}{T(K)}$.

\begin{tabular}{|l|c|c|c|}
\hline Sample & $\log \eta_{\infty}[\mathbf{d P a} \cdot \mathbf{s}]$ & $\mathbf{T}_{\mathbf{c}}[\mathbf{K}]$ & $\alpha$ \\
\hline $\mathrm{A}$ & $0.73 \pm 0.01$ & $731.0 \pm 0.1$ & $3.5 \pm 0$ \\
\hline $\mathrm{Ta} 1$ & $0.68 \pm 0.00$ & $746.8 \pm 0.1$ & $3.5 \pm 0$ \\
\hline $\mathrm{Nb} 0.1$ & $0.69 \pm 0.00$ & $732.8 \pm 0.1$ & $3.5 \pm 0$ \\
\hline $\mathrm{Nb} 1$ & $0.56 \pm 0.00$ & $743.9 \pm 0.1$ & $3.5 \pm 0$ \\
\hline $\mathrm{Nb} 2$ & $0.41 \pm 0.00$ & $755.1 \pm 0.1$ & $3.5 \pm 0$ \\
\hline
\end{tabular}

Table 4. Parameters $\log \eta_{\infty}$ and $T_{c}$ obtained by fitting the viscosity graphs with the Avramov-Milchevequation with $\alpha=3.5$.

may be predicted by the screw dislocation or $2 \mathrm{D}$ surface nucleation model ${ }^{31,32}$. Corresponding to Nascimento et al. the screw dislocation model is most likely for lithium disilicate ${ }^{33}$. However, it is also appropriate to display the deeply undercooled region, which is solely investigated in this paper, in Arrhenius coordinates and to perform a linear approximation ${ }^{33}$. For this reason, the crystal growth velocities were fitted by the following equation:

$$
\log \left(U, \frac{\mu m}{h}\right)=C_{1}+\frac{10^{3} \cdot C_{2}}{T(K)}
$$

with $\mathrm{U}=$ crystal growth velocity, $\mathrm{C}_{1}$ and $\mathrm{C}_{2}=$ constants.

The corresponding parameters $\mathrm{C}_{1}$ and $\mathrm{C}_{2}$ are listed in Table 3 .

As the additions of niobium and tantalum oxide to stoichiometric lithium disilicate glass lead to an increase in the viscosity, it seems likely that the drop of the crystal growth velocities is due to the higher viscosities. In order to check this assumption, the crystal growth velocities of the samples were compared at specific viscosity values. For this purpose, viscosities values obtained by beam bending and rotation viscometry were fitted by the Avramov-Milchev-equation. This enabled the calculation of viscosity values of the uncrystallized glass at temperatures where usually crystallization would occur. The fitting parameters $\log \eta_{\infty}, T_{c}$ and $\alpha$ of the samples are shown in Table 4. For each sample, several temperatures were calculated at which viscosity has a given value. At these temperatures, the growth rates were determined from the corresponding Arrhenius plot in Fig. 1b). In Fig. 1c), it is shown that the crystal growth velocities of the tantalum- and niobium-containing samples are much smaller also at the same viscosity than in the base glass.

First approximation: the viscosity depends solely on temperature. In order to further investigate the effect of the viscosity on the crystal growth, the viscosities of the samples should be considered as a function of the transformation degree $\mathrm{x}$, i.e. the crystallized fraction. The transformation degree is determined from a DTA profile by 


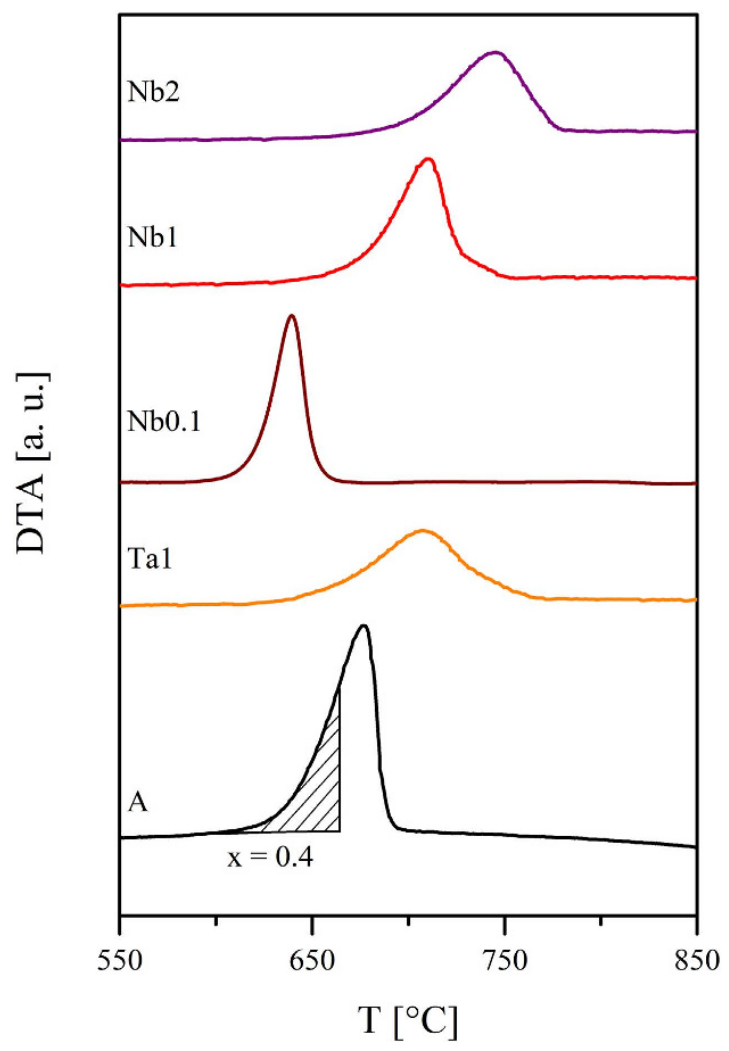

Figure 2. DTA profiles of the glasses. The shaded area in the crystallization peak of glass A corresponds to a transformation degree $\mathrm{x}$ of 0.4 . The transformation degree is the ratio of the partial area at a certain temperature to the total area of the crystallization peak.

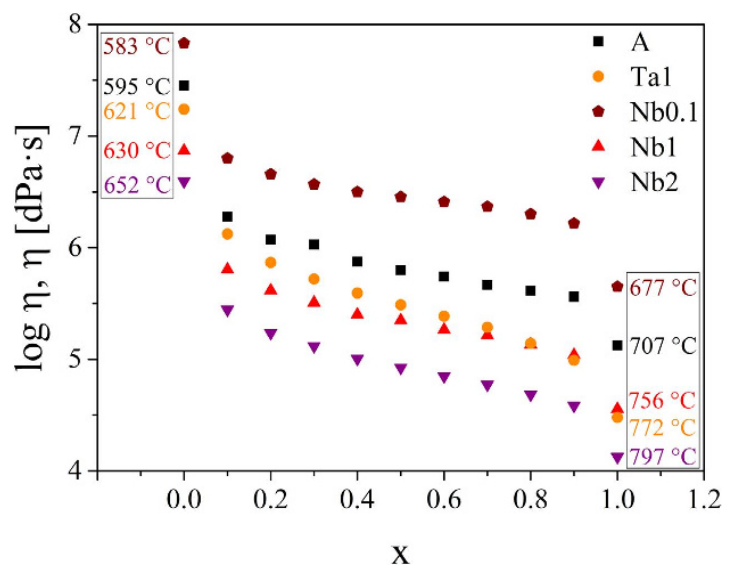

Figure 3. Viscosities as a function of the transformation degree $\mathrm{x}$ in case of the incorporation of the added oxides $\mathrm{Nb}_{2} \mathrm{O}_{5}$ or $\mathrm{Ta}_{2} \mathrm{O}_{5}$ into the lithium disilicate crystals. It should be mentioned that the behavior during a non-isothermal heat treatment is considered. For this reason the onset and endset temperatures are denoted.

taking the ratio of the partial area at a certain temperature to the total area of the crystallization peak. In Fig. 2, the crystallization peaks in the DTA profiles of the studied samples as well as a schematic of the determination of the transformation degree are shown. It becomes apparent that in the case of the doped samples, the onset of the crystallization peak is shifted to higher temperatures, except for sample Nb0.1, and hence, the temperatures belonging to a particular transformation degree are totally different. In Fig. 3, the viscosities as a function of the transformation degree are illustrated. Here, the viscosities at the respective temperatures were determined from the fit with the Avramov-Milchev-equation. In this case, as a first approximation, solely the effect of changing temperatures is taken into account and the viscosity of the glass melt is considered to be not affected by changing glass compositions. Since the crystallization degree determined from DTA-scans is considered, non-isothermal 


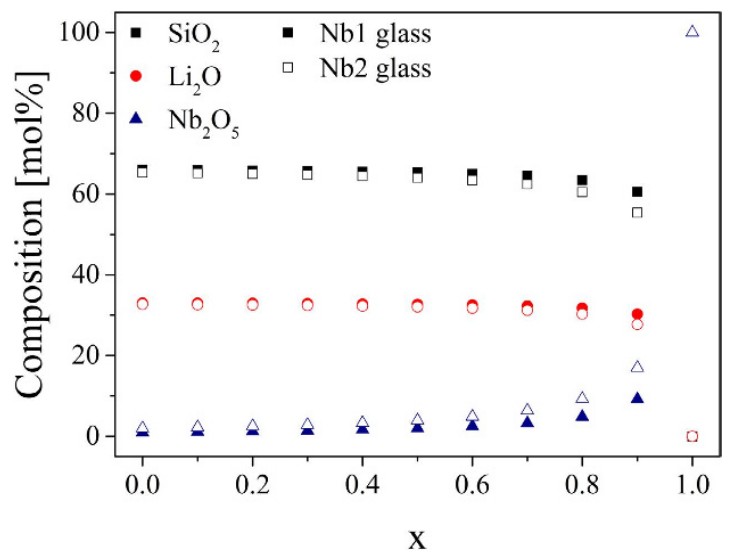

Figure 4. Molar composition of the residual glass matrix as a function of the transformation degree $x$. While the filled symbols describe the behavior of sample Nb1, the open symbols stand for the change in the composition of sample $\mathrm{Nb} 2$.

\begin{tabular}{|c|c|c|c|c|c|c|c|c|c|}
\hline \multirow[b]{2}{*}{$\mathbf{x}$} & \multicolumn{3}{|c|}{ Nb0.1 glass } & \multicolumn{3}{|c|}{$\mathrm{Nb1/Ta1}$ glass } & \multicolumn{3}{|c|}{ Nb2 glass } \\
\hline & $\mathrm{Li}_{2} \mathrm{O}$ & $\mathrm{SiO}_{2}$ & $\mathrm{Nb}_{2} \mathrm{O}_{5}$ & $\mathrm{Li}_{2} \mathrm{O}$ & $\mathrm{SiO}_{2}$ & $\mathrm{Nb}_{2} \mathrm{O}_{5} / \mathrm{Ta}_{2} \mathrm{O}_{5}$ & $\mathrm{Li}_{2} \mathrm{O}$ & $\mathrm{SiO}_{2}$ & $\mathrm{Nb}_{2} \mathrm{O}_{5}$ \\
\hline 0 & 33.3 & 66.6 & 0.10 & 33 & 66 & 1 & 32.67 & 65.33 & 2 \\
\hline 0.1 & 33.3 & 66.59 & 0.11 & 32.96 & 65.93 & 1.11 & 32.59 & 65.19 & 2.22 \\
\hline 0.2 & 33.29 & 66.58 & 0.12 & 32.92 & 65.84 & 1.25 & 32.50 & 65.01 & 2.49 \\
\hline 0.3 & 33.29 & 66.57 & 0.14 & 32.86 & 65.72 & 1.42 & 32.39 & 64.78 & 2.83 \\
\hline 0.4 & 33.28 & 66.56 & 0.17 & 32.78 & 65.56 & 1.66 & 32.24 & 64.47 & 3.29 \\
\hline 0.5 & 33.27 & 66.53 & 0.20 & 32.67 & 65.35 & 1.98 & 32.03 & 64.05 & 3.92 \\
\hline 0.6 & 33.25 & 66.50 & 0.25 & 32.51 & 65.02 & 2.46 & 31.72 & 63.43 & 4.85 \\
\hline 0.7 & 33.22 & 66.44 & 0.33 & 32.25 & 64.50 & 3.26 & 31.21 & 62.42 & 6.37 \\
\hline 0.8 & 33.17 & 66.33 & 0.50 & 31.73 & 63.46 & 4.81 & 30.25 & 60.49 & 9.26 \\
\hline 0.9 & 33.00 & 66.01 & 0.99 & 30.28 & 60.55 & 9.17 & 27.68 & 55.37 & 16.95 \\
\hline 1.0 & 0 & 0 & 100 & 0 & 0 & 100 & 0 & 0 & 100 \\
\hline
\end{tabular}

Table 5. Calculated molar composition of the residual glass matrix as a function of the transformation degree $x$.

behavior is illustrated. For this reason, the on- and endset temperatures of the respective crystallization peak are added for a better understanding.

While the viscosities decrease strongly at the beginning of the crystallization, the decrease weakens in case of higher transformation degrees and then is again highly pronounced. Moreover, the crystallization of the doped samples starts at a lower viscosity than in the base glass, with exception of sample Nb0.1.

Second approximation: the viscosity depends on the composition and changes during the course of the crystallization. The results illustrated in Figs $1 \mathrm{c}$ and 3 are based on the assumption that the viscosity solely depends on the temperature and is not affected by changing compositions. Niobium or tantalum are not incorporated into the lithium disilicate crystals, as indicated by the X-ray diffraction patterns ${ }^{28}$. Hence, niobium (or tantalum) is expelled from the crystallization front leading to a continuous enrichment of the remaining glass matrix with niobium or tantalum during the course of the crystallization process. For this reason, the viscosity of the residual glass matrix has to be related to the transformation degree which requires the determination of the composition of the residual glass matrix for $x>0$. The composition was calculated from the ratio of the remaining $\mathrm{SiO}_{2}, \mathrm{Li}_{2} \mathrm{O}$ and $\mathrm{Nb}_{2} \mathrm{O}_{5}$ concentrations at a certain transformation degree to their initial concentrations. The molar composition of the residual glass matrix as a function of the transformation degree is shown in Fig. 4 for the niobium-containing samples (the exact values are summarized in Table 5). The filled symbols belong to Nb1 glass and the filled symbols to $\mathrm{Nb} 2$ glass. Since the change in the molar composition of sample Nb0.1 is extremely small, sample Nb0.1 is not considered in Fig. 4. It is assumed that the chemical composition in the residual glassy phase is homogeneous, i.e. diffusion coefficients of the corresponding ions are much higher than the self-diffusion coefficient of the main building units, so that the profiles around the growing crystals are not formed. The change in the composition is the same in the samples $\mathrm{Nb} 1$ and $\mathrm{Ta} 1$. At the beginning of the crystallization process, a slight decrease in the molar percentage of $\mathrm{Li}_{2} \mathrm{O}$ and $\mathrm{SiO}_{2}$ is observed while the molar percentage of $\mathrm{Nb}_{2} \mathrm{O}_{5}$ increases. At a transformation degree of 0.5 , the molar composition of sample $\mathrm{Nb} 1$ and hence the viscosity is the same as for the composition of sample $\mathrm{Nb} 2$ at $\mathrm{x}=0$. For a transformation degree, higher than 0.5 , the decrease in the molar percentage of 


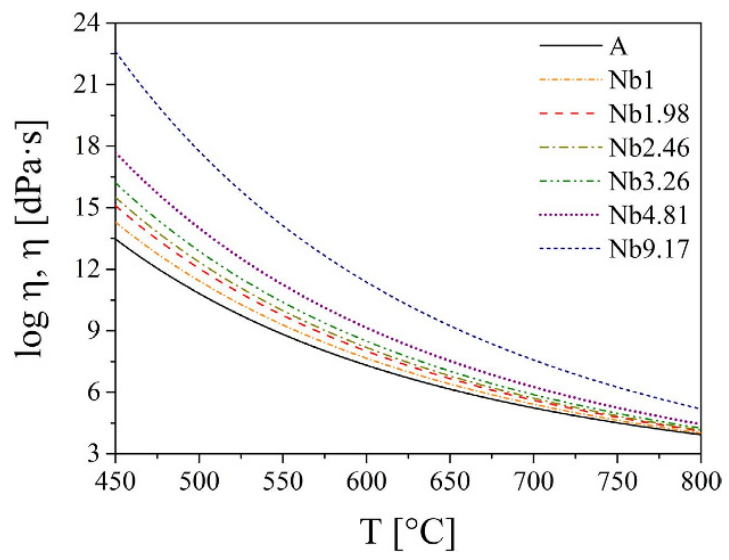

Figure 5. Viscosities of the base glass $A$ and the niobium-containing glasses. The viscosities of samples $A$ and $\mathrm{Nb} 1$ were measured by beam-bending and rotation viscometry. The remaining viscosities are interpolated from the measured ones.

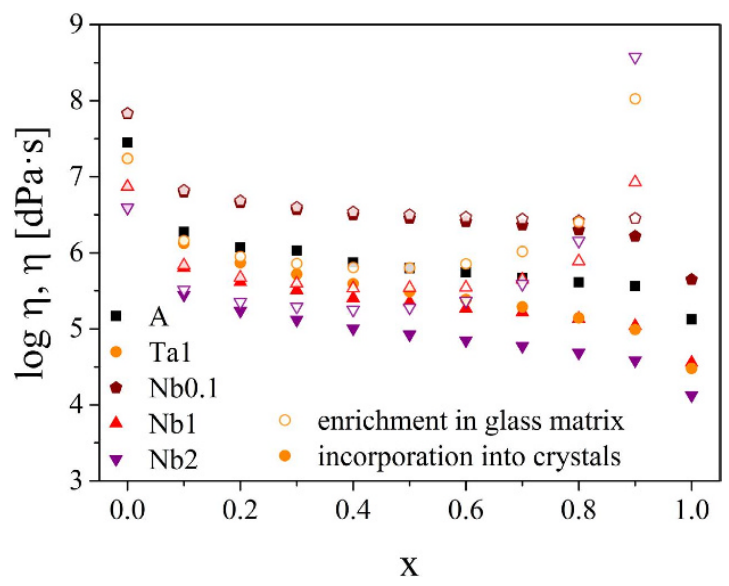

Figure 6. Viscosities as a function of the transformation degree $\mathrm{x}$ in case of the crystallization of lithium disilicate without incorporation of niobium or tantalum. It is assumed that niobium or tantalum ions are homogeneously distributed in the residual glass matrix and do not lead to an accumulation at the crystallization front.

$\mathrm{Li}_{2} \mathrm{O}$ and $\mathrm{SiO}_{2}$ as well as the increase in the molar percentage of $\mathrm{Nb}_{2} \mathrm{O}_{5}$ is intensified. At the end, lithium disilicate crystals and a residual glassy phase with a high concentration of niobium or tantalum oxide exist.

The viscosities of the samples $\mathrm{A}, \mathrm{Nb} 1, \mathrm{Nb} 2$ and $\mathrm{Ta} 1$ were measured using beam-bending and rotation viscometry and fitted using the Avramov-Milchev-equation at which the parameter $\alpha$ was kept constant $(\alpha=3.5)$. This was done due to the fact that $\alpha$ remained almost unchanged for small concentrations $c$ during the fitting procedure. Moreover, $\log \eta_{\infty}$ and $\mathrm{T}_{\mathrm{c}}$ depend linearly on $\mathrm{c}$ : $\mathrm{T}_{\mathrm{c}}(\mathrm{c})=732+12 \mathrm{c}$ and $\log \eta_{\infty}(\mathrm{c})=0.72-0.15 \mathrm{c}$ for the niobium-containing samples as well as $\mathrm{T}_{c}(\mathrm{c})=731+16 \mathrm{c}$ and $\log \eta_{\infty}(\mathrm{c})=0.74-0.075 \mathrm{c}$ for the tantalum-containing samples. Therefore, a continuous dependency of the viscosity on both the temperature and the concentration $\mathrm{c}$ is given. Hence, the viscosities of the residual glass matrix were interpolated using the before mentioned equations.

In Fig. 5, the measured viscosities of the base glass $\mathrm{A}$ and the niobium-containing sample $\mathrm{Nb} 1$ as well as the interpolated viscosities of the residual glass matrix are shown for different $\mathrm{Nb}_{2} \mathrm{O}_{5}$ concentrations. The respective labels stand for the molar percentage of niobium oxide. The addition of $\mathrm{Nb}_{2} \mathrm{O}_{5}$ leads to a notable increase in viscosity and the effect is most pronounced at temperatures close to $\mathrm{T}_{\mathrm{g}}$, i.e. in the temperature range where the nucleation rate is high, and gets smaller in the temperature range of crystal growth.

In Fig. 6, the transformation degree is correlated with the interpolated viscosities of the residual glass matrix (open symbols, enrichment in the glass matrix). The results of Fig. 3, i.e. the case of incorporation into the crystals, are also presented for comparison (filled symbols). At the beginning of the crystallization process, the viscosity of the glass matrix initially drops strongly as it is the case in Fig. 3. However, the viscosities are higher if niobium or tantalum is enriched in the glassy matrix than for the first approximation in which the effect of changing composition was not taken into account. The difference between the two approximations gets more pronounced with an increasing degree of transformation. For a transformation degree higher than 0.4 , the viscosities 


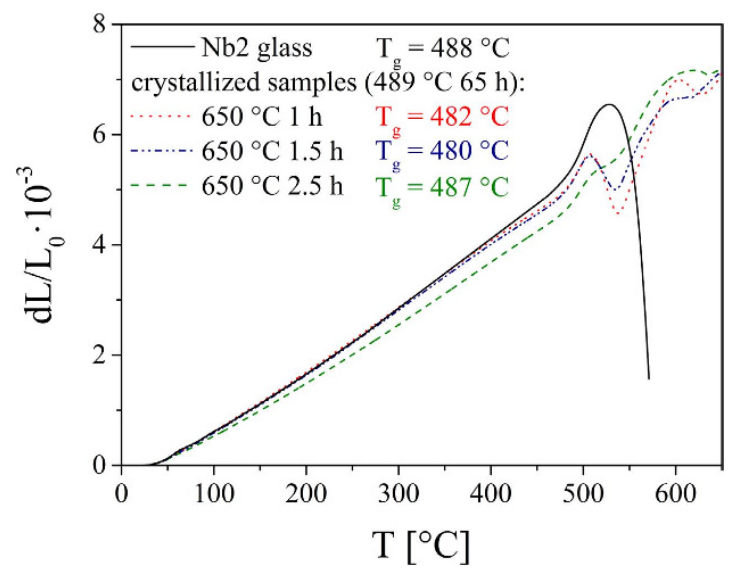

Figure 7. Dilatometry results of the glass $\mathrm{Nb} 2$ and $\mathrm{Nb} 2$ samples heat treated at $489^{\circ} \mathrm{C}$ for $65 \mathrm{~h}$ and $650^{\circ} \mathrm{C}$ for different times. Hence, the glass transition temperature of the residual glass matrix was determined as a function of the crystallization degree.

of the residual glass matrix increase again strongly as the molar percentage of niobium or tantalum oxide in the glass matrix increases. In the case of the small niobium oxide concentration of $0.1 \mathrm{~mol} \%$, the increase in viscosity only occurs at a higher transformation degree and the differences between the two approximations are not as pronounced. However, the results are based on the assumption that niobium or tantalum are homogeneously distributed in the glass matrix. Moreover, in this model an enrichment of the added oxides at the crystallization front is excluded.

In the previous paragraphs, the non-isothermal crystallization process was regarded. However, based on these results it might be assumed that during an isothermal crystallization of the non-stoichiometric glasses Nb0.1, $\mathrm{Nb} 1, \mathrm{Nb} 2$ and Ta1, the composition of the residual glassy matrix also varies and hence, their viscosity. Therefore, pre-nucleated cylindrical samples were heat treated at a certain growth temperature for different times to obtain different crystallization degrees ( $\mathrm{Nb} 1$ and Ta1: nucleation at $489^{\circ} \mathrm{C}$ for $2 \mathrm{~h}$ and growth at $640^{\circ} \mathrm{C}$; $\mathrm{Nb} 2$ : nucleation at $489^{\circ} \mathrm{C} 65 \mathrm{~h}$ and growth at $650^{\circ} \mathrm{C}$ ) and the glass transition temperature $\mathrm{T}_{\mathrm{g}}$ of the residual glass matrix was determined by dilatometry. In Fig. 7, the results from dilatometry are shown for crystallized $\mathrm{Nb} 2$ samples along with the corresponding glass sample. While the glass sample has a $\mathrm{T}_{\mathrm{g}}$ at $488^{\circ} \mathrm{C}$, the $\mathrm{T}_{\mathrm{g}}$ initially decreases with increasing holding time at the growth temperature, i.e. increasing crystallization degree, and then again increases. The differences in $\mathrm{T}_{\mathrm{g}}$ are extremely small and within the limits of error (temperature and evaluation error). However, the same behavior was also observed for the other glasses and it is in agreement with the results of Fig. 6 . In addition, in Fig. 7 it can be seen that the well pronounced softening point of the glass sample does not occur in the crystallized samples. Instead, only a slight softening point followed by a further increase in dilatation and a second softening are observed probably due to the high crystallization degree which impedes softening.

Activation energy for crystallization. The activation energy for crystallization may be determined from the Kissinger ${ }^{34}$ or Ozawa ${ }^{35}$ equations. In these relations, the shift of the crystallization temperature to higher values and the increasing area under the crystallization peak with increasing heating rate are used. Both equations are valid if surface crystallization is the predominant crystallization mechanism or for $\mathrm{n}=\mathrm{m}$ ( $\mathrm{n}$ - Avrami parameter which corresponds to the nucleation and growth mechanism, m - dimensionality of crystal growth) ${ }^{36}$. The latter is applicable if the number of nuclei is independent of the applied heating rate, i.e. crystallization occurs from the same number of nuclei at different heating rates ${ }^{37}$. The condition $n=m$ is fulfilled since the number of nuclei, counted after annealing samples to the development temperature with different heating rates in the heating stage of the laser scanning microscope, was approximately equal. The obtained Kissinger plots are shown in Fig. 8 and the calculated activation energies for crystallization are summarized in Table 6 along with the activation enthalpies for crystal growth $\mathrm{E}_{\mathrm{a}}$ calculated from Arrhenius plots of the crystal growth velocities. It should be mentioned that the activation energy computed using the Kissinger method describes the overall crystallization process including nucleation and crystal growth. In Table 6, it can be seen that the activation energies $\mathrm{E}_{\text {Kissinger }}$ of the doped samples are lower than that of the base glass and that with increasing niobium concentration, the activation energy also decreases. By contrast, the activation enthalpy for crystal growth of the sample Ta1 is slightly smaller and those of the niobium-containing samples are slightly to considerably higher than that of sample $\mathrm{A}^{28}$.

\section{Discussion}

In the past decades, stoichiometric lithium disilicate glass has been the subject of numerous investigations concerning nucleation and crystal growth kinetics $3,5,6,38,39$, especially regarding the applicability of the classical nucleation theory $y^{4,40-42}$. Moreover, the effect of small amounts of additives which promote nucleation (e.g. water ${ }^{43}$, platinum ${ }^{4-47}$ or $\mathrm{P}_{2} \mathrm{O}_{5}{ }^{4-50}$ ) on the nucleation rates as well as on the crystal growth velocities was studied. In the case of the addition of water, the effect was reported to be related to a decrease of the kinetic barrier for nucleation due to lower viscosities, rather than changing the thermodynamic barrier of nucleation, i.e. decreasing the surface energy ${ }^{43}$. Krüger et al. added up to $12 \mathrm{wt} \% \mathrm{ZrO}_{2}$ to a $\mathrm{SiO}_{2} / \mathrm{Li}_{2} \mathrm{O}\left(-\mathrm{K}_{2} \mathrm{O} / \mathrm{Al}_{2} \mathrm{O}_{3} / \mathrm{P}_{2} \mathrm{O}_{5}\right)$ glass and detected that an increasing zirconia concentration leads to an increase in the nucleation rates by about two orders of magnitude ${ }^{51}$. 


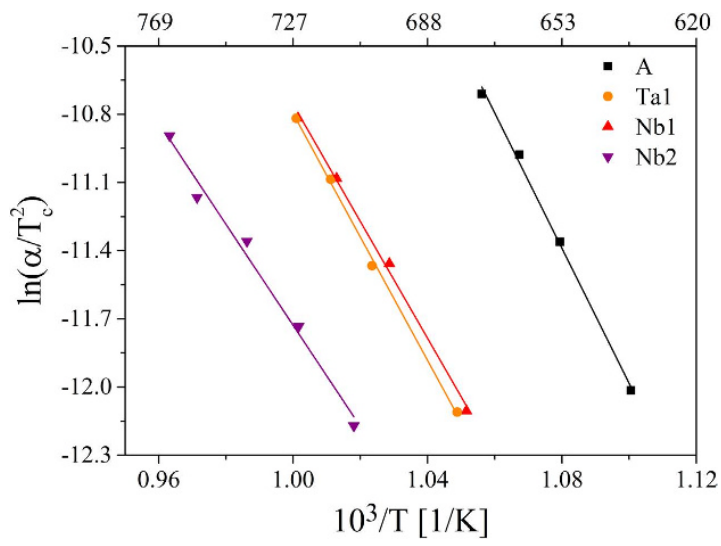

Figure 8. Kissinger plots of the samples $\mathrm{A}, \mathrm{Ta} 1, \mathrm{Nb} 1$ and $\mathrm{Nb} 2$. The activation energy for crystallization was determined from the slope of the regression line.

\begin{tabular}{|l|c|c|c|c|}
\hline Sample & $\mathbf{E}_{\text {Kissinger }}[\mathbf{k J} / \mathbf{m o l}]$ & Preexponential factor & Direction & $\mathbf{E}_{\mathbf{a}}[\mathbf{k J} / \mathbf{m o l}]^{\mathbf{a}}$ \\
\hline $\mathrm{A}$ & $247 \pm 9$ & 20.73 & & $283 \pm 4$ \\
\hline Ta1 & $226 \pm 6$ & 16.35 & $\mathrm{a}$ & $263 \pm 8$ \\
\hline & & & $\mathrm{b}$ & $269 \pm 8$ \\
\hline $\mathrm{Nb} 1$ & $214 \pm 8$ & 14.96 & $\mathrm{a}$ & $342 \pm 16$ \\
\hline & & & $\mathrm{b}$ & $348 \pm 15$ \\
\hline Nb2 & $185 \pm 12$ & 10.54 & $\mathrm{a}$ & $299 \pm 5$ \\
\hline & & & $\mathrm{b} / 2$ & $308 \pm 6$ \\
\hline
\end{tabular}

Table 6. Activation energies for crystallization determined by the Kissinger method. The activation enthalpies for crystal growth $\mathrm{E}_{\mathrm{a}}$ obtained from Arrhenius plots of the crystal growth velocities are shown for

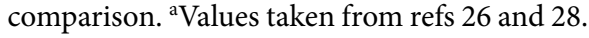

Here, it was assumed that $\mathrm{ZrO}_{2}$ likely affects the thermodynamic barrier of nucleation (see Eq. 1) ${ }^{51}$. Matusita and Tashiro measured nucleation rates in alkali disilicate glasses ( $\mathrm{Li}, \mathrm{Na}$ and $\mathrm{K}$ ) and observed the highest nucleation rates in $\mathrm{Li}_{2} \mathrm{O} \cdot 2 \mathrm{SiO}_{2}$ glass ${ }^{52}$. This effect was attributed to the great free energy difference in this system, i.e. to the thermodynamic driving force and not related to the viscosity or the interfacial energy ${ }^{52}$.

However, the effect of nucleation inhibitors leading to decreasing nucleation rates and crystal growth velocities as well as to increasing induction times for steady-state nucleation has only been scarcely investigated in the past. Matusita and Tashiro ${ }^{53}$ as well as Schlesinger and Lynch ${ }^{54}$ have already analyzed the effect of small concentrations of oxides on the nucleation kinetics of lithium disilicate glass and in these publications the nucleation inhibition was attributed to higher viscosities of the glasses. However, a recent paper showed that the addition of $\mathrm{Al}_{2} \mathrm{O}_{3}, \mathrm{La}_{2} \mathrm{O}_{3}$ and $\mathrm{TiO}_{2}$ to stoichiometric lithium disilicate glass leads to a drastically decrease in the nucleation rates at certain viscosity values ${ }^{26}$. Moreover, it was observed that the effects are much more pronounced than the increase in viscosity would provoke ${ }^{26}$. The addition of $\mathrm{ZrO}_{2}$ concentrations to $\mathrm{Li}_{2} \mathrm{O} \cdot 2 \mathrm{SiO}_{2}$-glass leads to remarkably smaller nucleation rates and interestingly for zirconia concentrations $>2 \mathrm{~mol} \%$, volume nucleation was not observed and instead only surface crystallization was detected ${ }^{27}$. The absence of volume nucleation was correlated with the reduced glass transition temperature and is explained by the higher work for critical cluster formation in the bulk than at the surface at temperatures near $\mathrm{T}_{\mathrm{g}}{ }^{5-57}$. Nucleation inhibition occurs also in $\mathrm{Nb}_{2} \mathrm{O}_{5^{-}}$ or $\mathrm{Ta}_{2} \mathrm{O}_{5}$-doped lithium disilicate glasses which was related to a decreased structural similarity between glass and crystal as it is assumed that the added oxides are incorporated as distorted $\mathrm{MO}_{6}$-octahedra $(\mathrm{M}=\mathrm{Nb}, \mathrm{Ta})$ in the glass matrix ${ }^{28}$. Furthermore, in all cases a higher stability against crystallization is observed which is associated with slower crystallization ${ }^{28}$. Moreover, the additives lead to a remarkable decrease of the crystal growth velocities $^{26-28}$. Recently, in lithium disilicate glasses doped with $\mathrm{CeO}_{2}$, cerium accumulations between the lamellae of the lithium disilicate crystals and at the crystallization front were detected using fluorescence and scanning electron microscopy resulting in decreased crystal growth velocities ${ }^{58}$.

According to the Classical Nucleation Theory $(\mathrm{CNT})$, the steady-state volume nucleation rate $\mathrm{I}_{\text {st }}$ can be described by the following equation ${ }^{59}$

$$
I_{s t}=I_{0} \cdot \exp \left[-\frac{W^{*}+\Delta G_{D}}{k_{B} T}\right] \text { with } I_{0}=2 N_{l} \frac{k_{B} T}{h}\left(\frac{a^{2} \sigma}{k_{B} T}\right)^{1 / 2}
$$

where $\mathrm{I}_{0}$ is a preexponential term consisting of the number of structural units $\mathrm{N}_{\mathrm{l}}$ per unit volume of the melt with a mean size $\mathrm{a}$, the Boltzmann constant $\mathrm{k}_{\mathrm{B}}$, the Planck constant $\mathrm{h}$ and the surface energy of the nucleus/ 

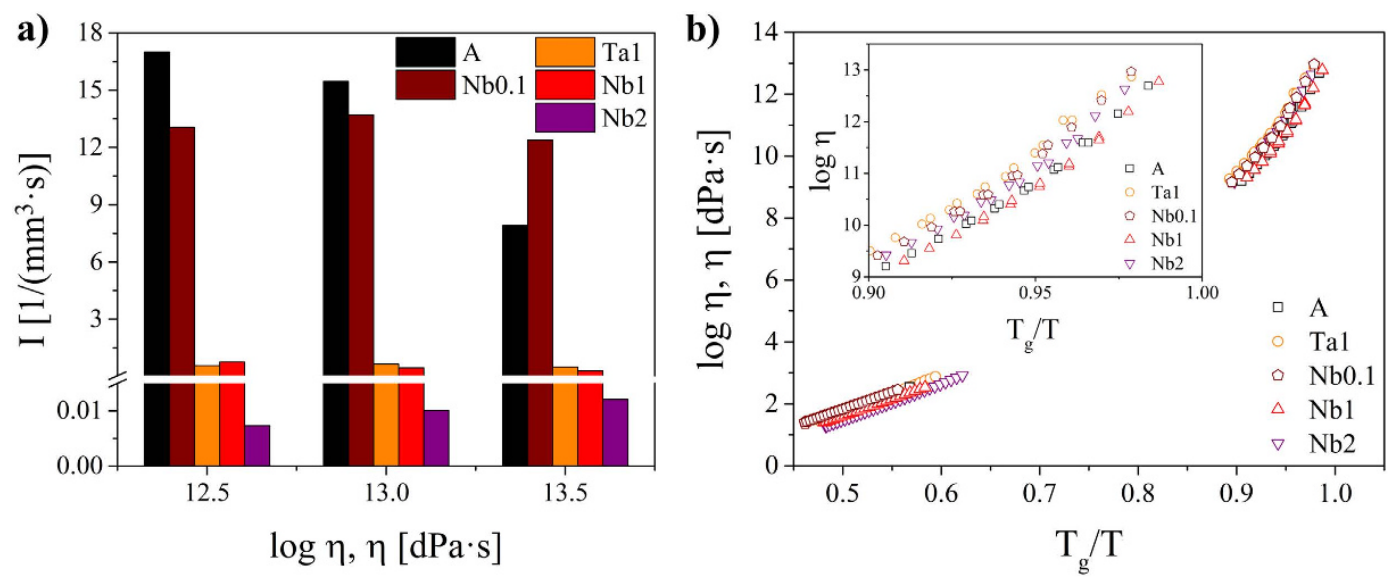

Figure 9. (a) Steady-state nucleation rates of the studied samples for different viscosities (12.5, 13 and $13.5 \mathrm{dPa} \cdot \mathrm{s})$ and $(\mathbf{b})$ viscosities as a function of the ratio $\mathrm{T}_{\mathrm{g}} / \mathrm{T}\left(\mathrm{T}_{\mathrm{g}}\right.$ determined by DTA).

melt interface per unit area $\sigma$. While $\mathrm{W}^{*}$ is the thermodynamic barrier for nucleation, i.e. the work of critical cluster formation, $\Delta \mathrm{G}_{\mathrm{D}}$ describes the kinetic barrier for nucleation, i.e. the activation energy for the transport of a structural unit across the nucleus/melt interface. Assuming a spherical nucleus the thermodynamic barrier for nucleation $\mathrm{W}^{*}$ can be described by

$$
W^{*}=\frac{16}{3} \pi \frac{\sigma^{3}}{\Delta G_{V}^{2}}
$$

The thermodynamic driving force for crystallization $\Delta \mathrm{G}_{\mathrm{V}}$ which is the difference between the free energies of the glass and the crystalline phase per unit volume ${ }^{60}$ can be estimated from the melting enthalpy per unit volume of the crystal $\Delta \mathrm{H}_{\mathrm{m}}$ at the melting temperature $\mathrm{T}_{\mathrm{m}}$ assuming that $\Delta \mathrm{C}_{\mathrm{p}}=0$ (difference of the molar heat capacities of melt and crystal at constant pressure $)^{39}$ :

$$
\Delta G_{V}=\frac{\Delta H_{m}\left(T_{m}-T\right)}{T_{m}}
$$

The kinetic barrier for nucleation $\Delta \mathrm{G}_{\mathrm{D}}$ is often described by an effective diffusion coefficient $\mathrm{D}$ (ref. 50) which is given by:

$$
D=\frac{k_{B} T \lambda^{2}}{h} \exp \left(-\frac{\Delta G_{D}}{k_{B} T}\right)
$$

Here, $\lambda$ describes a jump distance of the order of atomic dimensions. Moreover, $\mathrm{D}$ can be related to the viscosity $\eta$ by the following equation ${ }^{50}$ :

$$
D=\frac{k_{B} T}{3 \pi \lambda \eta}
$$

The time required to reach steady-state nucleation, i.e. the time-lag for nucleation $\tau$, is given by equation (9) if the initial concentration of critical and sub-critical nuclei is negligible ${ }^{57}$ :

$$
\tau=\frac{16 \pi}{h} \frac{\sigma}{\Delta G_{V}^{2} a^{4}} \exp \left(\frac{\Delta G_{D}}{k_{B} T}\right)\left(\tau=\frac{6}{\pi^{2}} t_{\text {ind }}\right)
$$

According to equation (4), small crystal nucleation rates might be due to an increase in both the thermodynamic $\left(W^{*}\right)$ and the kinetic barrier for nucleation $\left(\Delta G_{D}\right)$. In Fig. 9a), the steady-state nucleation rates of the base glass $\mathrm{A}$ are compared to those of $\mathrm{Nb} 0.1$ and $\mathrm{Ta} 1$ at specific viscosity values $(12.5,13$ and $13.5 \mathrm{dPa} \cdot \mathrm{s})$. It becomes apparent that the nucleation rates of Tal are up to two orders of magnitude lower at the same viscosity values while those of $\mathrm{Nb} 0.1$ are in a similar range as the base glass A. Moreover, it can be seen that the nucleation rates of $\mathrm{Ta} 1$ and $\mathrm{Nb} 1$ are approximately the same while those of $\mathrm{Nb} 2$ are one order of magnitude lower. In part b), the beam bending and rotation viscosities are presented as a function of $\mathrm{T}_{\mathrm{g}} / \mathrm{T}\left(\mathrm{T}_{\mathrm{g}}\right.$ determined by $\mathrm{DTA}^{26,28}$ ) and it can be seen that the viscosities of the glasses match very well. In the inset, showing $\mathrm{T}_{\mathrm{g}} / \mathrm{T}$-values between 0.9 and 1.0 (i.e. the range of nucleation above $\mathrm{T}_{\mathrm{g}}$ ), it is visible that there are only minimal deviations between the glasses which, however, are not related to the nucleation rates and in addition the slight viscosity differences might not provoke such high discrepancies in the nucleation rates. Based on these facts, the viscosity has to be excluded as a key factor for nucleation inhibition. 


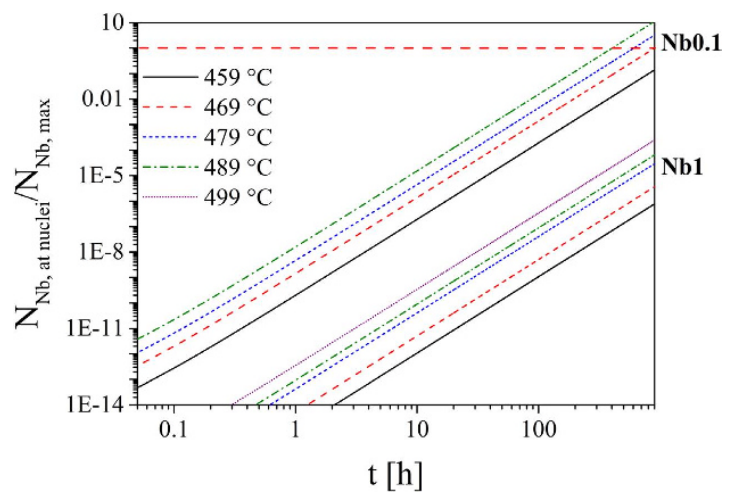

Figure 10. Ratio of the number of $\mathrm{Nb}$-particles required for a complete coverage of the nuclei $\left(\mathrm{N}_{\mathrm{Nb} \text {,at nuclei }}\right)$ and the number of available $\mathrm{Nb}$-particles in the considered volume $\left(\mathrm{N}_{\mathrm{Nb} \text {,max }}\right)$ versus holding time at different nucleation temperatures for $\mathrm{Nb0.1}$ and $\mathrm{Nb} 1$.

The formation of critical nuclei and the subsequent crystal growth is strongly affected by the attachment rate, also called impingement rate, of building units at the surface of the nuclei and the growing crystals, respectively. According to refs 61 and 62, the steady-state nucleation rate and the nucleation time-lag are also defined as (see for comparison equations (4) and (9))

$$
\begin{gathered}
I_{s t}=D_{k} \Gamma N_{l} \exp \left(-\frac{W^{*}}{k_{B} T}\right) \\
\tau=\frac{4}{\pi^{3}} \cdot \frac{1}{\Gamma^{2} D_{k}}
\end{gathered}
$$

While $\mathrm{D}_{\mathrm{k}}$ is the molecular flux to the critical nucleus ${ }^{61}, \Gamma$ describes the Zeldovich factor which converts an equilibrium expression into a steady-state expression ${ }^{63}$. The flux $D_{k}$ is given by the product of the surface area of the nucleus $A_{k}$, the impingement rate per unit area $Z$ of the structural units to the nucleus and a numerical factor $\zeta$ which characterizes the steric hindrance at the nucleus interface during the incorporation of the building units $^{61}$. According to ref. 61 , for undercooled melts the impingement rate $\mathrm{Z}$ is

$$
Z \cong \operatorname{const} \zeta \frac{k_{B} T}{d_{0} \eta}
$$

where $d_{0}$ is the mean atomic distance. Since the viscosity as key factor for nucleation inhibition was excluded in the last paragraph, the incorporation of the building units seems to be hindered by the layer of the added oxides at the interface which is indicated by the decrease in the steady-state nucleation rates with increasing dopant concentration. Furthermore, it was shown that a minor concentration of $0.1 \mathrm{~mol} \% \mathrm{Nb}_{2} \mathrm{O}_{5}$ may slightly affect the nucleation rates which is contradictory to a study of James et al. ${ }^{64}$ who investigated the effect of different crucible and stirrer materials as well as the purity of the raw materials on crystal nucleation kinetics in lithium disilicate glass. They observed that the quantities of impurities present in ordinary batch materials and different melt conditions do not remarkably affect the nucleation rates. However, the present results indicate that the effect of impurities on nucleation and crystal growth kinetics is not negligible.

Based on the $\mathrm{Nb}_{2} \mathrm{O}_{5}$ concentration in the glasses, the glass density and the nucleation rates, it is possible to estimate whether the niobium concentration is sufficient for a complete coverage of the nuclei during the nucleation process. In this calculation, the lithium disilicate nuclei are assumed to be spherical. Moreover, since the exact attachment process and hence the packing factor is unknown a hexagonal packing of the $\mathrm{Nb}$-O-groups (factor 0.907 ) at the surface of the nuclei is supposed in the following. In these calculations a nuclei size distribution at the respective nucleation temperature is considered. In Fig. 10, the ratio of the number of Nb-particles which is necessary for a complete coverage of the nuclei $\left(\mathrm{N}_{\mathrm{Nb} \text {,at nuclei }}\right)$ and the number of available $\mathrm{Nb}$-particles in the considered volume $\left(\mathrm{N}_{\mathrm{Nb} \text {, max }}\right)$ is shown as a function of the holding time at different nucleation temperatures. The crystal growth velocities at the nucleation temperatures are extrapolated using the regression parameters stated in Table 3. In the case of samples $\mathrm{Nb} 1$ and $\mathrm{Nb} 2$, the growth direction a is regarded. For a better understanding, it should be mentioned that if the ratio $\mathrm{N}_{\mathrm{Nb} \text {,at nuclei }} / \mathrm{N}_{\mathrm{Nb} \text {,max }}$ is higher than 1, the number of Nb-particles in this volume is too low for a complete coverage of the nuclei (highlighted by a red line). It is visible that the holding time for reaching the equilibrium between required and available particles decreases with increasing nucleation temperature. However, in the case of $\mathrm{Nb} 1$ and $\mathrm{Nb} 2$ (not shown in this graph) only a fraction of the available $\mathrm{Nb}$-particles can be attached at the nuclei interface, even after $900 \mathrm{~h}$, due to the low nucleation rates and crystal growth velocities. Since the nucleation rates of $\mathrm{Nb} 1$ and $\mathrm{Nb} 2$ differ by one order of magnitude, the ratio $\mathrm{N}_{\mathrm{Nb} \text {,at }}$ nuclei $/ \mathrm{N}_{\mathrm{Nb} \text {, max }}$ is also one order of magnitude lower in sample $\mathrm{Nb} 2$. In sample $\mathrm{Nb} 2$, the higher niobium concentration is not sufficient to compensate the lower number of nuclei. In comparison to the hexagonal packing which is described before, a quadratic packing of the $\mathrm{Nb}$-O-groups with a packing factor of 0.785 would result in a higher 

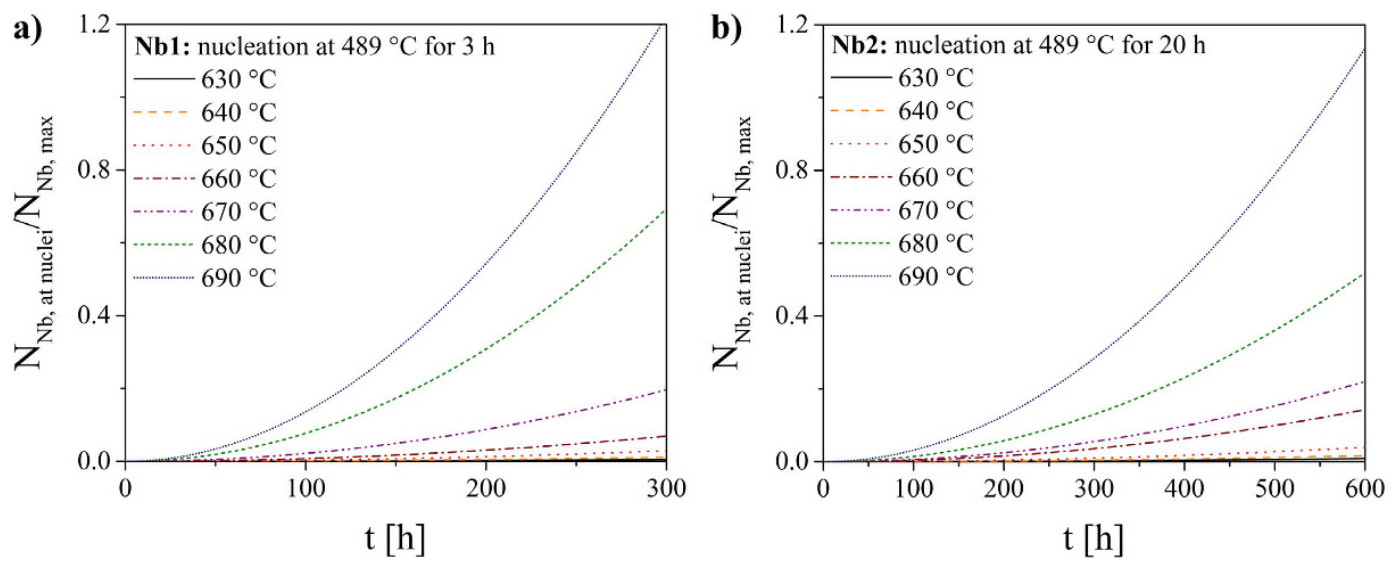

Figure 11. Ratio $\mathrm{N}_{\mathrm{Nb} \text {,at nuclei }} / \mathrm{N}_{\mathrm{Nb} \text {,max }}$ as a function of the holding time at various growth temperatures. The calculations are based on the number of nuclei formed during a nucleation treatment at $489^{\circ} \mathrm{C}$ for $3 \mathrm{~h}(\mathrm{Nb} 1)$ and $20 \mathrm{~h}(\mathrm{Nb} 2)$.

$\mathrm{N}_{\mathrm{Nb} \text {,at nuclei }}$ at the respective nucleation temperature and time and hence the ratio $\mathrm{N}_{\mathrm{Nb} \text {,at nuclei }} / \mathrm{N}_{\mathrm{Nb} \text {,max }}$ would be increased. As a result, the nuclei surface would be covered earlier by the $\mathrm{Nb}-\mathrm{O}$-diffusion barrier.

In Fig. 11, the number of niobium particles during isothermal crystal growth at $630-690^{\circ} \mathrm{C}$ is considered. The number of existing nuclei was calculated for the applied nucleation treatments at $489^{\circ} \mathrm{C}$ for $3 \mathrm{~h}(\mathrm{Nb} 1)$ and $20 \mathrm{~h}(\mathrm{Nb} 2)$ and the crystal growth velocities published in ref. 28 were used. In the case of sample $\mathrm{Nb} 1 \mathrm{and} \mathrm{Nb} 2$ extremely long holding times at the growth temperatures are necessary for reaching the point where the number of Nb-particles is too low for covering the nuclei. However, the calculated times are unrealistic as the samples are completely crystallized after a few hours.

Based on these calculations, it can be concluded that the niobium concentrations, especially in the samples $\mathrm{Nb} 1$ and $\mathrm{Nb} 2$, are sufficient to provoke a niobium oxide layer at the interface and hence may decrease the impingement rate.

At a first glance, the nucleation inhibition might also be a result of a higher thermodynamic barrier of nucleation which, in principle might be caused by a higher specific interface energy of the nucleus/melt interface $\sigma$, or a smaller thermodynamic driving force for crystallization $\Delta G_{V}$. The added oxide might only affect the specific interface energy if it occurs at the interface crystal/residual glass matrix. This, however, should only be the case if it is thermodynamically advantageous. As a result, the specific interface energy would be decreased. Since the added oxides are adsorbed at the interface, it is likely that the surface energy of the nucleus/melt interface is decreased by the additives. Otherwise, the layer at the crystal interface would not be formed as it is thermodynamically disadvantageous. Unfortunately, due to the lack of a reliable method, the interfacial energy is not experimentally accessible. Therefore, experimental nucleation data are fitted to the CNT. However, according to CNT, it is supposed that the thermodynamic properties of the nuclei are similar to the corresponding macroscopic phase (capillarity approximation). For this reason, the nucleus/melt surface energy is treated as a planar interface of the macro-phase ${ }^{60}$. Moreover, besides the size dependency, the temperature dependency of the surface energy is mostly not considered ${ }^{60}$. Although the surface energy of glass melts shows only a slight temperature dependency (usually $\sim 1 \% / 100 \mathrm{~K}$ ), this might also affect the nucleation process.

According to Eq. 2, the thermodynamic barrier for nucleation $\mathrm{W}^{*}$ is also increased by a diminished thermodynamic driving force for crystallization $\Delta \mathrm{G}_{\mathrm{V}}$. According to refs 65 and 66, a deviation of the nucleus composition from that of the stoichiometric glass or the initial glass composition generally results in a decreased $\Delta \mathrm{G}_{\mathrm{v}}$. Hence, the addition of niobium or tantalum oxide or any other component to the glass composition should alone be sufficient to decrease the thermodynamic driving force and hence to decrease the nucleation rate. Small concentrations of additives, however, should not have a large effect.

Furthermore, the formation of stoichiometric crystals may proceed through the nucleation of solid solutions ${ }^{55,65}$. Based on the aforementioned publications, the nucleation of lithium disilicate solid solutions may not be completely excluded in the studied glasses. Moreover, it is also possible that trace quantities of niobium or tantalum are incorporated into the lithium disilicate crystals, without detecting them with the applied methods due to the detection limits. The thermodynamic driving force can be further decreased by the occurrence of metastable phases which may also result in a deviating nucleus composition ${ }^{59}$. In the studied lithium disilicate system, the precipitation of the metastable lithium metasilicate in $\mathrm{Li}_{2} \mathrm{O} \cdot 2 \mathrm{SiO}_{2}$ glasses has been a heavily discussed issue in the past decades (e.g. refs 2 and 67-70). However, the precipitation of lithium metasilicate (in the early stages of crystallization) was not observed in our glass compositions. Elastic stresses evolving during the course of the crystallization due to a difference between the densities of the glass and the crystal might lead to a decrease in $\Delta \mathrm{G}_{\mathrm{V}}$, especially for temperatures lower than the so-called decoupling temperature $\left(\mathrm{T}_{\mathrm{d}} \sim 1.2 \mathrm{~T}_{\mathrm{g}}\right)^{59}$. It was shown for lithium disilicate glass that the steady-state nucleation rates may be decreased by up to two orders of magnitude due to elastic stresses ${ }^{71}$. However, the comparison of the densities of the studied glasses with the crystal density $\left(\rho_{\text {crystal }}=2.45 \mathrm{~g} / \mathrm{cm}^{3}\right.$, ref. 72$)$, assuming the precipitation of stoichiometric lithium disilicate crystals, shows that 


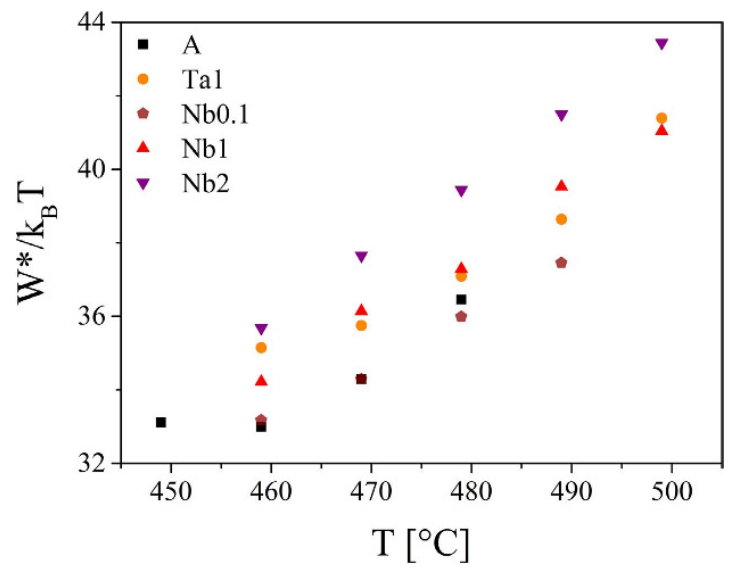

Figure 12. Thermodynamic barrier for nucleation as a function of the temperature.

\begin{tabular}{|l|c|c|c|}
\hline Sample & $\mathbf{T}_{\mathbf{m}}\left[{ }^{\circ} \mathbf{C}\right]$ & $\Delta \mathbf{H}_{\mathrm{m}}\left[\mathbf{J} / \mathbf{m}^{3}\right]$ & $\boldsymbol{\sigma}_{\infty}\left[\mathbf{J} / \mathbf{m}^{2}\right]$ \\
\hline $\mathrm{A}$ & 1034 & $1.19 \cdot 10^{9}$ & 0.245 \\
\hline $\mathrm{Ta} 1$ & 1010 & $1.00 \cdot 10^{9}$ & 0.206 \\
\hline $\mathrm{Nb} 0.1$ & 1033 & $9.56 \cdot 10^{8}$ & 0.196 \\
\hline $\mathrm{Nb} 1$ & 951 & $9.95 \cdot 10^{8}$ & 0.206 \\
\hline $\mathrm{Nb} 2$ & 955 & $1.03 \cdot 10^{9}$ & 0.212 \\
\hline
\end{tabular}

Table 7. Melting temperatures $T_{m}$, melting enthalpies $\Delta H_{m}$ and surface energies $\sigma_{\infty}$ of the studied samples. The measurement error of $\mathrm{T}_{\mathrm{m}}$ is approximately $\pm 5 \mathrm{~K}$. The error in the estimation of $\sigma_{\infty}$ is about $0.02 \mathrm{~J} / \mathrm{m}^{2}$.

the difference in the densities is highest for sample $\mathrm{A}$ and decreases if $\mathrm{Nb}_{2} \mathrm{O}_{5}$ or $\mathrm{Ta}_{2} \mathrm{O}_{5}$ are added. For this reason, the effect of elastic stresses on the thermodynamic driving force cannot be responsible for the observed effect.

If a breakdown of the Stokes-Einstein-equation at temperatures lower than the decoupling temperature $\left(\mathrm{T}_{\mathrm{d}} \sim 1.2 \mathrm{~T}_{\mathrm{g}}\right)$ is neglected and the kinetic barrier for nucleation is connected with the glass viscosity, equation (4) can be transformed to ${ }^{30,57}$ :

$$
I_{s t}=\frac{A T}{\eta} \exp \left(-\frac{W^{*}}{k_{B} T}\right) \text { with } A=\frac{n_{V}^{2} k_{B}}{3 \pi}
$$

where $\mathrm{n}_{\mathrm{v}}$ is the number of formula units per unit volume of the glass. Hence, the thermodynamic barrier for nucleation can be calculated as follows:

$$
\frac{W^{*}}{k_{B} T}=-\ln \left(\frac{I_{s t} \eta}{A T}\right)
$$

Based on the fact that neither niobium nor tantalum is incorporated into the lithium disilicate crystals, the preexponential factor $\mathrm{A}$ is the same for all studied glasses. According to ref. $4, \mathrm{n}_{\mathrm{v}}$ is typically $10^{29} \mathrm{~m}^{-3}$. Fig. 12 shows $\mathrm{W}^{\star} / \mathrm{k}_{\mathrm{B}} \mathrm{T}$ as a function of the temperature for the different glasses. It becomes apparent that the thermodynamic barrier of the doped samples is considerably higher than that of the base glass. Only sample Nb0.1 which exhibits nucleation rates in the same order of magnitude compared with sample $A$ has similar $\mathrm{W}^{\star} / \mathrm{k}_{\mathrm{B}} \mathrm{T}$-values. The small increase in the thermodynamic barrier for nucleation of sample A at temperatures below $460^{\circ} \mathrm{C}$ was also observed in refs 30 and 57.

As mentioned in the previous paragraphs, the thermodynamic barrier for nucleation is determined by the thermodynamic driving force $\Delta \mathrm{G}_{\mathrm{V}}$ and the interfacial energy crystal/glassy matrix $\sigma$. Using the melting enthalpy per unit volume $\Delta \mathrm{H}_{\mathrm{m}}$ and the melting temperatures $\mathrm{T}_{\mathrm{m}}, \Delta \mathrm{G}_{\mathrm{V}}$ can be computed using the Turnbull approximation in equation (6). Since $\Delta \mathrm{H}_{\mathrm{m}}$ is proportional to the melting peak area, it can be roughly estimated by DSC. The absolute measurement error of $\mathrm{T}_{\mathrm{m}}$ is approximately $\pm 5 \mathrm{~K}$. Furthermore, $\Delta \mathrm{H}_{\mathrm{m}}$ of sample $\mathrm{A}$ is in a good agreement with the literature data $\left(57.3 \mathrm{~kJ} / \mathrm{mol} \equiv 9.36 \cdot 10^{8} \mathrm{~J} / \mathrm{m}^{3}\right.$ (ref. 42$)$ and $57.4 \mathrm{~kJ} / \mathrm{mol} \equiv 9.38 \cdot 10^{8} \mathrm{~J} / \mathrm{m}^{3}$ (used in ref. 4 , average of the values given in refs 73 and 74)). As shown in Table 7, the values of $\Delta H_{m}$ for the doped samples are clearly smaller than for sample A.

As can be seen in Fig. 13, the thermodynamic driving force of the base glass is the highest, while the samples $\mathrm{Nb} 1$ and $\mathrm{Nb} 2$ show the lowest $\Delta \mathrm{G}_{\mathrm{V}}$. It should be mentioned that the Turnbull expression gives an upper bound for $\Delta \mathrm{G}_{\mathrm{V}}(\mathrm{T})$ and is only valid if $\Delta \mathrm{C}_{\mathrm{p}}=0$.

The interfacial energy $\sigma$ can be calculated using the semi-empirical Turnbull-Skapski-equation ${ }^{59}$. In this equation, it is assumed that $\sigma_{\infty}$ does not depend on the temperature and the size of the nucleus. 


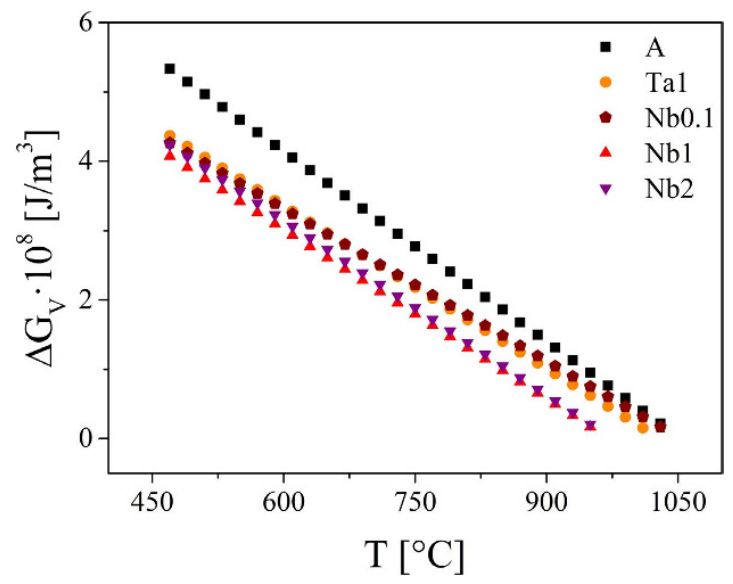

Figure 13. Thermodynamic driving force per unit volume of the lithium disilicate crystallization as a function of the temperature.

$$
\sigma_{\infty}=\frac{\alpha \cdot \Delta H_{m}}{N_{A}^{1 / 3} V_{m}^{2 / 3}}
$$

While $\alpha$ is an empirical dimensionless coefficient (for lithium disilicate glass $\alpha=0.44$, ref. 30), $\mathrm{N}_{\mathrm{A}}$ is Avogadro's number. In the literature, $\sigma_{\infty}$ of $\mathrm{Li}_{2} \mathrm{O} \cdot 2 \mathrm{SiO}_{2}$ was calculated from the slope of the plot $\ln (\mathrm{I} \eta / \mathrm{T}) \mathrm{vs}$. $1 /\left(\Delta \mathrm{G}^{2} \mathrm{~T}\right.$ ) yielding the following results: $0.196 \mathrm{~J} / \mathrm{m}^{2}$ (Matusita \& Tashiro ${ }^{52}$ ), $0.207 \mathrm{~J} / \mathrm{m}^{2}$ (Weinberg et al. ${ }^{42}$ ) and $0.198-0.209 \mathrm{~J} / \mathrm{m}^{2}$ (Zanotto \& James ${ }^{4}$ ). In Table 7, it is visible that the calculation of $\sigma_{\infty}$ of the undoped glass using equation (15) results in the slightly higher value 0.245 . Moreover, $\sigma_{\infty}$ is slightly decreased by the addition of $\mathrm{Nb}_{2} \mathrm{O}_{5}$ or $\mathrm{Ta}_{2} \mathrm{O}_{5}$ at which the values are all within the limits of error.

Hence, the assumptions that the thermodynamic driving force as well as the interfacial energy are diminished could be confirmed by the calculations. Although $\sigma$ is included in equation (5) with the third power, the decrease of $\Delta \mathrm{G}_{\mathrm{V}}$ seems to be the determining factor for the increase of $\mathrm{W}^{\star} / \mathrm{k}_{\mathrm{B}} \mathrm{T}$ (Fig. 12).

As shown in Fig. 6, during the course of the crystallization, the composition of the residual glass matrix changes in the non-stoichiometric samples leading to an increase of the viscosity. For simplification, the model is based on the assumption that niobium or tantalum oxide is homogeneously distributed in the glassy matrix. However, as mentioned previously, the added oxides are adsorbed at the crystal/glass matrix interface forming a diffusion barrier. The self-limited crystal growth due to a diffusion zone has been already reported for e.g. oxyfluoride glasses ${ }^{7,16}$, apatite ${ }^{12}$ and quartz from the systems $\mathrm{MgO}-\mathrm{Al}_{2} \mathrm{O}_{3}-\mathrm{SiO}_{2}{ }^{10,75}$ or $\mathrm{Li}_{2} \mathrm{O}-\mathrm{Al}_{2} \mathrm{O}_{3}-\mathrm{SiO}_{2}{ }^{9}$. Here, the composition in the vicinity of the crystals changes leading to a drastic change of the glass structure ${ }^{15}$. If an enrichment of network former occurs near the nuclei, crystal growth will decelerate with time. The crystal growth velocities remarkably decrease by the added oxides and in addition with increasing niobium concentration (Fig. 1). Hence, these effects may be likely related to an enrichment of the additives at the crystallization front as explained in the previous paragraph. This leads to a decrease of the interfacial energy crystal/glassy phase which alone should not decrease, but increase the nucleation rate. This effect, however, is overcompensated by the decrease in the thermodynamic driving force and supposedly most important by an increase in the kinetic barrier, $\Delta G_{D}$, and a lower impingement rate $Z$, due to the blocking effect of the niobium or tantalum enriched layer around the subcritical nuclei.

In summary, this leads to deceleration of nucleation and crystal growth and to an increase in the induction period.

\section{Conclusions}

Steady-state nucleation rates and crystal growth velocities of stoichiometric lithium disilicate glass significantly decrease by the addition of small niobium or tantalum oxide concentrations. Even a minor concentration of $0.1 \mathrm{~mol} \% \mathrm{Nb}_{2} \mathrm{O}_{5}$ provokes a slight inhibition of the nucleation and growth kinetics. In the course of non-isothermal crystallization of the glasses, the viscosity of the residual glass matrix initially decreases and then remarkably increases with increasing crystallization degree hindering further crystal growth. This is based on the assumption that the niobium and tantalum ions are not incorporated into the lithium disilicate crystals but homogeneously distributed in the glass matrix. In the case of an isothermal heat treatment of the samples, a similar viscosity trend is observed. However, it was shown that the added oxides are accumulated at the crystallization front resulting in a lower interfacial surface energy. Since a lower interfacial surface energy would alone provoke higher nucleation rates, this has to be compensated by a decreased thermodynamic driving force. The viscosity has to be excluded as key factor as the nucleation rates of the doped samples are even drastically lower at the same viscosity values. However, due to the accumulation of the additives at the crystallization front, the interface of the nuclei is blocked and the attachment of further building units is decelerated. Hence, the impingement rate is lowered with increasing additive concentration. 
In summary, the addition of small amounts of the studied oxides enables the control of the crystallization behavior of the glasses in a wide range. This is solely limited by a maximum additive concentration at which the ions are incorporated into the crystals.

\section{References}

1. Glasser, F. P. Crystallisation of lithium disilicate from $\mathrm{Li}_{2} \mathrm{O}-\mathrm{SiO}_{2}$ glasses. Phys. Chem. Glasses 8, 224-232 (1967).

2. Hench, L. L., Frieman, S. W. \& Kinser, D. L. The early stages of crystallisation in a $\mathrm{Li}_{2} \mathrm{O}-2 \mathrm{SiO}_{2}$ glass. Phys. Chem. Glasses 12, 58-63 (1971).

3. James, P. Kinetics of crystal nucleation in lithium silicate glasses. Phys. Chem. Glasses 15, 95-105 (1974).

4. Zanotto, E. D. \& James, P. F. Experimental tests of the classical nucleation theory for glasses. J. Non-Cryst. Solids 74, 373-394 (1985).

5. Barker, M. F., Wang, T.-H. \& James, P. F. Nucleation and growth kinetics of lithium disilicate and lithium metasilicate in lithia-silica glasses. Phys. Chem. Glasses 29, 240-248 (1988).

6. Deubener, J., Brückner, R. \& Sternitzke, M. Induction time analysis of nucleation and crystal growth in di- and metasilicate glasses. J. Non-Cryst. Solids 163, 1-12 (1993).

7. Rüssel, C. Nanocrystallization of $\mathrm{CaF}_{2}$ from $\mathrm{Na}_{2} \mathrm{O} / \mathrm{K}_{2} \mathrm{O} / \mathrm{CaO} / \mathrm{CaF}_{2} / \mathrm{Al}_{2} \mathrm{O}_{3} / \mathrm{SiO}_{2}$ Glasses. Chem. Mater. 17, 5843-5847 (2005).

8. de Almeida, R. P. F., Bocker, C. \& Rüssel, C. Size of $\mathrm{CaF}_{2}$ Crystals Precipitated from Glasses in the $\mathrm{Na}_{2} \mathrm{O} / \mathrm{K}_{2} \mathrm{O} / \mathrm{CaO} / \mathrm{CaF}_{2} / \mathrm{Al}_{2} \mathrm{O}_{3} / \mathrm{SiO}_{2}$ System and Percolation Theory. Chem. Mater. 20, 5916-5921 (2008).

9. Wurth, R., Muñoz, F., Müller, M. \& Rüssel, C. Crystal growth in a multicomponent lithia aluminosilicate glass. Mater. Chem. Phys. 116, 433-437 (2009).

10. Dittmer, M., Müller, M. \& Rüssel, C. Self-organized nanocrystallinity in $\mathrm{MgO}-\mathrm{Al}_{2} \mathrm{O}_{3}-\mathrm{SiO}_{2}$ glasses with $\mathrm{ZrO}_{2}$ as nucleating agent. Mater. Chem. Phys. 124, 1083-1088 (2010).

11. Wisniewski, W., Carl, R., Völksch, G. \& Rüssel, C. Mullite Needles Grown from a $\mathrm{MgO} / \mathrm{Al}_{2} \mathrm{O}_{3} / \mathrm{TiO}_{2} / \mathrm{SiO}_{2} / \mathrm{B}_{2} \mathrm{O}_{3} / \mathrm{CaO}_{\mathrm{Glass}} \mathrm{Melt}$ : Orientation and Diffusion Barriers. Cryst. Growth Des. 11, 784-790 (2011).

12. Hill, R. G. et al. The early stages of nucleation and crystallisation of an apatite glass-ceramic: Evidence for nano-scale crystallisation. J. Non-Cryst. Solids 356, 2935-2941 (2010).

13. Avramov, I., Rüssel, C., Kolkovska, N. \& Georgiev, I. Crystallization kinetics and network rigidity. J. Phys.: Condens. Matter 20, 335203 (2008).

14. Bocker, C., Avramov, I. \& Rüssel, C. Viscosity and diffusion of barium and fluoride in $\mathrm{Na}_{2} \mathrm{O} / \mathrm{K}_{2} \mathrm{O} / \mathrm{Al}_{2} \mathrm{O}_{3} / \mathrm{SiO}_{2} / \mathrm{BaF}$ glasses. Chem . Phys. 369, 96-100 (2010).

15. Bocker, C., Rüssel, C. \& Avramov, I. Crystal growth in non-isochemical, highly viscous liquids and percolation theory. Chem. Phys. 406, 50-54 (2012).

16. Bhattacharyya, S. et al. Experimental Evidence of Self-Limited Growth of Nanocrystals in Glass. Nano Lett. 9, 2493-2496 (2009).

17. Bhattacharyya, S. et al. Direct Evidence of Al-Rich Layers around Nanosized $\mathrm{ZrTiO}_{4}$ in Glass: Putting the Role of Nucleation Agents in Perspective. Cryst. Growth Des. 10, 379-385 (2010).

18. Raghuwanshi, V. S., Hoell, A., Bocker, C. \& Rüssel, C. Experimental evidence of a diffusion barrier around BaF $\mathrm{F}_{2}$ nanocrystals in a silicate glass system by ASAXS. CrystEngComm 14, 5215-5223 (2012).

19. Hoell, A. et al. ASAXS study of $\mathrm{CaF}_{2}$ nanoparticles embedded in a silicate glass matrix. J. Appl. Crystallogr. 47, 60-66 (2014).

20. Raghuwanshi, V. S., Rüssel, C. \& Hoell, A. Crystallization of $\mathrm{ZrTiO}_{4}$ Nanocrystals in Lithium-Alumino-Silicate Glass Ceramics: Anomalous Small-Angle X-ray Scattering Investigation. Cryst. Growth Des. 14, 2838-2845 (2014).

21. Raghuwanshi, V. S. et al. Magnetic nanocrystals embedded in silicate glasses studied by polarized SANS. J. Non-Cryst. Solids $\mathbf{3 8 5}$, 24-29 (2014)

22. Zdaniewski, W. DTA and X-Ray Analysis Study of Nucleation and Crystallization of $\mathrm{MgO}-\mathrm{Al}_{2} \mathrm{O}_{3}-\mathrm{SiO}_{2} \mathrm{Glasses} \mathrm{Containing} \mathrm{ZrO}_{2}$, $\mathrm{TiO}_{2}$, and $\mathrm{CeO}_{2}$. J. Am. Ceram. Soc. 58, 163-169 (1975).

23. Dittmer, M. \& Rüssel, C. Colorless and high strength $\mathrm{MgO} / \mathrm{Al}_{2} \mathrm{O}_{3} / \mathrm{SiO}_{2}$ glass-ceramic dental material using zirconia as nucleating agent. J. Biomed. Mater. Res. 100B, 463-470 (2012).

24. Hu, A.-M., Liang, K.-M., Wang, G., Zhou, F. \& Peng, F. Effect of nucleating agents on the crystallization of $\mathrm{Li}_{2} \mathrm{O}-\mathrm{Al}_{2} \mathrm{O}_{3}-\mathrm{SiO}_{2}$ system glass. J. Therm. Anal. Calorim. 78, 991-997 (2004).

25. Shao, H., Liang, K., Zhou, F., Wang, G. \& Hu, A. Microstructure and mechanical properties of $\mathrm{MgO}_{-} \mathrm{Al}_{2} \mathrm{O}_{3}-\mathrm{SiO}_{2}-\mathrm{TiO}{ }_{2}$ glass-ceramics. Mater. Res. Bull. 40, 499-506 (2005).

26. Thieme, K. \& Rüssel, C. Nucleation inhibitors - The effect of small concentrations of $\mathrm{Al}_{2} \mathrm{O}_{3}, \mathrm{La}_{2} \mathrm{O}_{3}$ or TiO $\mathrm{TiO}_{2}$ on nucleation and crystallization of lithium disilicate. J. Eur. Ceram. Soc. 34, 3969-3979 (2014).

27. Thieme, K. \& Rüssel, C. Nucleation and growth kinetics and phase analysis in zirconia-containing lithium disilicate glass. J. Mater. Sci. 50, 1488-1499 (2015).

28. Thieme, K. \& Rüssel, C. The effect of niobium- and tantalum oxide on nucleation and growth kinetics in lithium disilicate glasses. Mater. Chem. Phys. 162, 354-363 (2015).

29. Kissinger, H. E. Reaction Kinetics in Differential Thermal Analysis. Anal. Chem. 29, 1702-1706 (1957).

30. Cabral, A. A., Fokin, V. M. \& Zanotto, E. D. Nanocrystallization of fresnoite glass. II. Analysis of homogeneous nucleation kinetics. J. Non-Cryst. Solids 343, 85-90 (2004).

31. Doremus, R. H., Roberts, B. W. \& Turnbull, D. Growth and perfection of crystals (Wiley, 1958).

32. Burgner, L. L. \& Weinberg, M. C. Crystal growth mechanisms in inorganic glasses. Phys. Chem. Glasses 42, 184-190 (2001).

33. Nascimento, M. L. F., Fokin, V. M., Zanotto, E. D. \& Abyzov, A. S. Dynamic processes in a silicate liquid from above melting to below the glass transition. J. Chem. Phys. 135, 194703 (2011).

34. Kissinger, H. E. Variation of peak temperature with heating rate in differential thermal analysis. J. Res. Nat. Bur. Stand. 57, 217-221 (1956).

35. Ozawa, T. A modified method for kinetic analysis of thermoanalytical data. J. Therm. Anal. Calorim. 9, 369-373 (1976).

36. Pascual, M. J., Lara, C. \& Duran, A. Non-isothermal crystallisation kinetics of devitrifying $\mathrm{RO}-\mathrm{BaO}-\mathrm{SiO}{ }_{2}(\mathrm{R}=\mathrm{Mg}, \mathrm{Zn}) \mathrm{glasses}$. Phys. Chem. Glasses 47, 572-581 (2006).

37. Donald, I. W. Crystallization kinetics of a lithium zinc silicate glass studied by DTA and DSC. J. Non-Cryst. Solids 345-346, 120-126 (2004).

38. Burgner, L. L. \& Weinberg, M. C. An assessment of crystal growth behavior in lithium disilicate glass. J. Non-Cryst. Solids 279, 28-43 (2001).

39. Rüssel, C. \& Keding, R. A new explanation for the induction period observed during nucleation of lithium disilicate glass. J. NonCryst. Solids 328, 174-182 (2003).

40. Neilson, G. F. \& Weinberg, M. C. A test of classical nucleation theory: crystal nucleation of lithium disilicate glass. J. Non-Cryst. Solids 34, 137-147 (1979).

41. Rowlands, E. G. \& James, P. F. Analysis of steady state crystal nucleation rates in glasses. Part 2: Further comparison between theory and experiment for lithium disilicate glass. Phys. Chem. Glasses 20, 9-14 (1979).

42. Weinberg, M. C., Zanotto, E. D. \& Manrich, S. Classical nucleation theory with a size dependent interfacial tension: $\mathrm{Li}_{2} \mathrm{O} \cdot 2 \mathrm{SiO}_{2}$ crystal nucleation. Phys. Chem. Glasses 33, 99-102 (1992). 
43. Gonzalez-Oliver, C. J. R., Johnson, P. S. \& James, P. F. Influence of water content on the rates of crystal nucleation and growth in lithia-silica and soda-lime-silica glasses. J. Mater. Sci. 14, 1159-1169 (1979).

44. Cronin, D. \& Pye, L. D. Platinum catalyzed crystallization of $\mathrm{Li}_{2} \mathrm{O} \cdot 2 \mathrm{SiO}_{2}$ glass. J. Non-Cryst. Solids 84, 196-205 (1986).

45. Huang, W., Ray, C. S. \& Day, D. E. Dependence of the critical cooling rate for lithium-silicate glass on nucleating agents. J. Non-Cryst. Solids 86, 204-212 (1986).

46. Narayan, K. L., Kelton, K. F. \& Ray, C. S. Effect of Pt doping on nucleation and crystallization in $\mathrm{Li}_{2} \mathrm{O} \cdot 2 \mathrm{SiO}_{2}$ glass: experimental measurements and computer modeling. J. Non-Cryst. Solids 195, 148-157 (1996).

47. Ray, C. S. et al. Non-isothermal calorimetric studies of the crystallization of lithium disilicate glass. J. Non-Cryst. Solids 204, 1-12 (1996).

48. McMillan, P. W. Glass Ceramics (Academic Press, 1979).

49. James, P. F. Nucleation and Crystallization in Glasses (Advances in Ceramics) 4, (American Ceramic Society, 1982).

50. James, P. F. in Glasses and Glass-Ceramics (ed. Lewis, M. H.) 59-105 (Springer Netherlands, 1989).

51. Krüger, S., Deubener, J., Ritzberger, C. \& Höland, W. Nucleation Kinetics of Lithium Metasilicate in $\mathrm{ZrO}_{2}$-Bearing Lithium Disilicate Glasses for Dental Application. Int. J. Appl. Glass Sci. 4, 9-19 (2013).

52. Matusita, K. \& Tashiro, M. Rate of homogeneous nucleation in alkali disilicate glasses. J. Non-Cryst. Solids 11, 471-484 (1973).

53. Matusita, K. \& Tashiro, M. Effect of added oxides on the crystallisation of $\mathrm{Li}_{2} \mathrm{O} \cdot \mathrm{SiO}_{2}$ glasses. Phys. Chem. Glasses 14, 77-80 (1973).

54. Schlesinger, M. E. \& Lynch, D. C. Effect of VB and VIB oxides on nucleation parameters in lithium disilicate glass. J. Non-Cryst. Solids 108, 237-248 (1989).

55. Zanotto, E. D. \& Fokin, V. M. Recent studies of internal and surface nucleation in silicate glasses. Phil. Trans. R. Soc. Lond. A 361, 591-613 (2003)

56. Fokin, V. M., Zanotto, E. D. \& Schmelzer, J. W. P. Homogeneous nucleation versus glass transition temperature of silicate glasses. J. Non-Cryst. Solids 321, 52-65 (2003).

57. Fokin, V. M., Zanotto, E. D., Yuritsyn, N. S. \& Schmelzer, J. W. P. Homogeneous crystal nucleation in silicate glasses: A 40 years perspective. J. Non-Cryst. Solids 352, 2681-2714 (2006).

58. Thieme, K. \& Rüssel, C. $\mathrm{CeO}_{2}$ and $\mathrm{Y}_{2} \mathrm{O}_{3}$ as nucleation inhibitors in lithium disilicate glasses. J. Mater. Sci. 51, $989-999$ (2016).

59. Schmelzer, J. W. P. Nucleation Theory and Applications (Wiley-VCH, 2005).

60. Fokin, V. M. \& Zanotto, E. D. Crystal nucleation in silicate glasses: the temperature and size dependence of crystal/liquid surface energy. J. Non-Cryst. Solids 265, 105-112 (2000).

61. Gutzow, I. Induced crystallization of glass-forming systems: A case of transient heterogeneous nucleation, part 1. Contemp. Phys. 21, 121-137 (1980)

62. Gutzow, I., Kashchiev, D. \& Avramov, I. Nucleation and crystallization in glass-forming melts: Olds problems and new questions. J. Non-Cryst. Solids 73, 477-499 (1985).

63. Oxtoby, D. W. \& Kashchiev, D. A general relation between the nucleation work and the size of the nucleus in multicomponent nucleation. J. Chem. Phys. 100, 7665-7671 (1994).

64. James, P. F., Scott, B. \& Armstrong, P. Kinetics of crystal nucleation in lithium disilicate glass. A comparison between melts prepared in platinum and silica crucibles and between melts prepared from ordinary and high purity starting materials. Phys. Chem. Glasses 19, 24-27 (1978).

65. Fokin, V. M. et al. Mutant crystals in $\mathrm{Na}_{2} \mathrm{O} \cdot 2 \mathrm{CaO} \cdot 3 \mathrm{SiO}_{2}$ glasses. J. Non-Cryst. Solids 331, 240-253 (2003).

66. Fokin, V. M. \& Zanotto, E. D. Continuous compositional changes of crystal and liquid during crystallization of a sodium calcium silicate glass. J. Non-Cryst. Solids 353, 2459-2468 (2007).

67. Iqbal, Y., Lee, W. E., Holland, D. \& James, P. F. Metastable phase formation in the early stage crystallisation of lithium disilicate glass. J. Non-Cryst. Solids 224, 1-16 (1998).

68. Burgner, L. L., Weinberg, M. C., Lucas, P., Soares, P. C., Jr. \& Zanotto, E. D. XRD investigation of metastable phase formation in $\mathrm{Li}_{2} \mathrm{O}-2 \mathrm{SiO}_{2}$ glass. J. Non-Cryst. Solids 255, 264-268 (1999).

69. Burgner, L. L., Lucas, P., Weinberg, M. C., Soares, P. C., Jr. \& Zanotto, E. D. On the persistence of metastable crystal phases in lithium disilicate glass. J. Non-Cryst. Solids 274, 188-194 (2000).

70. Soares, P., Jr., Zanotto, E. D., Fokin, V. M. \& Jain, H. TEM and XRD study of early crystallization of lithium disilicate glasses. J. NonCryst. Solids 331, 217-227 (2003).

71. Schmelzer, J. W. P., Potapov, O. V., Fokin, V. M., Müller, R. \& Reinsch, S. The effect of elastic stress and relaxation on crystal nucleation in lithium disilicate glass. J. Non-Cryst. Solids 333, 150-160 (2004).

72. Zanotto, E. D. \& Müller, E. A simple method to predict the nucleation mechanism in glass. J. Non-Cryst. Solids 130, 220-221 (1991).

73. Takahashi, K. \& Yoshio, T. Thermodynamic quantities of alkali silicates in the temperature range from $25{ }^{\circ} \mathrm{C}$ to melting point. $J$. Ceram. Assoc. Jpn. 81, 524-533 (1973).

74. Stull, D. R. \& Prophet, H. JANAF Thermochemical Tables (National Bureau of Standards, Department of Commerce, Washington DC, 1971).

75. Dittmer, M., Yamamoto, C. F., Bocker, C. \& Rüssel, C. Crystallization and mechanical properties of $\mathrm{MgO} / \mathrm{Al}_{2} \mathrm{O}_{3} / \mathrm{SiO}_{2} / \mathrm{ZrO}_{2}$ glassceramics with and without the addition of yttria. Solid State Sci. 13, 2146-2153 (2011).

\section{Author Contributions}

K.T. prepared all figures, performed all measurements and took part in the analysis of the mechanism. I.A. took part in the analysis of the mechanism. C.R. was responsible for the coordination of the experiments and took part in the analysis of the mechanism. All authors reviewed the manuscript.

\section{Additional Information}

Competing financial interests: The authors declare no competing financial interests.

How to cite this article: Thieme, K. et al. The mechanism of deceleration of nucleation and crystal growth by the small addition of transition metals to lithium disilicate glasses. Sci. Rep. 6, 25451; doi: 10.1038/srep25451 (2016).

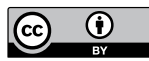

This work is licensed under a Creative Commons Attribution 4.0 International License. The images or other third party material in this article are included in the article's Creative Commons license, unless indicated otherwise in the credit line; if the material is not included under the Creative Commons license, users will need to obtain permission from the license holder to reproduce the material. To view a copy of this license, visit http://creativecommons.org/licenses/by/4.0/ 